\title{
DATOS Y CONTROL MÁS QUE CONOCIMIENTO Y COLABORACIÓN: LAS TIC EN LA EMPRESA CHILENA*
}

\author{
Claudio Ramos Zincke
}

Sobre la base de una investigación en 200 empresas manufactureras y de servicios, medianas y grandes, en este estudio se concluye que las empresas chilenas están privilegiando usos tradicionales de las tecnologías de la información y comunicación (TIC), esto es, como instrumentos de apoyo a la toma de decisiones y como medio de control, y hacen escaso uso de ellas para el desarrollo de la reflexividad, el aprendizaje organizacional y la gestión del conocimiento, que constituyen usos "avanzados". Se señala que esto representa un desarrollo parcial y desbalanceado en la implementación de estas tecnologías. Buscando explicar esta situación, se plantean hipótesis que remiten a factores tanto "técnicos" como "culturales". Los resultados empíricos revelan que algunos factores que influyen en un uso "avanzado" de las TIC son: la existencia de un contexto organizacional participativo, la inclusión de la empresa en redes de propiedad y, en particular, las vinculaciones de propiedad con compañías de países de industrialización avanzada. Los factores económicos y técnicos, por su parte, no aparecen como explicación suficiente ni primordial.

Claudio Ramos Zincke. Licenciado y Magister en Sociología, P. Universidad Católica de Chile. M.A. y Ph.D. in Sociology, University of Texas at Austin. Profesor del Departamento de Ciencias Sociales de la Universidad Alberto Hurtado y del Instituto de Sociología de la P. Universidad Católica de Chile.

* Este artículo presenta resultados obtenidos como parte de una investigación que ha contado con financiamiento de Fondecyt (Proyecto $\mathrm{N}^{\circ}$ 1020335) y con el apoyo de la University of Texas at Austin.

Estudios Públicos, 96 (primavera 2004). 


\section{Introducción}

$\mathrm{L}$

as últimas décadas han significado cambios sustanciales para las empresas en todo el mundo. Tales cambios, que han ido desde rediseños estructurales y reorientaciones estratégicas hasta cambios en la organización del trabajo, pueden interpretarse como dando forma a un nuevo "paradigma" organizacional, es decir, a una nueva forma de articularse de las empresas, tanto interna como externamente. En los debates académicos este paradigma ha recibido diferentes denominaciones, todas objeto de cuestionamiento. Aquí optamos por el de "postfordismo", el cual también es objeto de impugnación, pero que consideramos suficientemente ilustrativo y relativamente neutro, a diferencia de otros como los de "especialización flexible" (Piore y Sabel, 1984), o "toyotismo" (Dohse, Jurgens y Malsch, 1985), o "producción liviana" (Womack, Jones y Roos, 1990), o "sistema de producción antropocéntrico" (Charles, 1995), que se juegan por un particular aspecto u orientación de los cambios.

En este paradigma postfordista, que involucra peculiares rasgos de flexibilidad, adaptabilidad, interconexión en redes y reflexividad organizacional, uno de sus componentes nucleares es una nueva forma tecnológica - la tecnología informática y de la comunicación (TIC) — que alcanza su masificación en los años 80. Así, las aplicaciones de las TIC se han ido extendiendo a través de los procesos organizacionales, cubriendo desde las tareas de producción, en las plantas fabriles, hasta los procesos de gestión general de la empresa, permitiendo, además, el establecimiento de diversas formas de comunicación e interacción electrónica y fortaleciendo el desarrollo de redes externas.

Desde sus primeras manifestaciones empresariales de importancia, en la década de los 60, hasta ahora, esta tecnología ha experimentado notorias transformaciones y lo mismo ha ocurrido con sus potencialidades organizacionales. Hoy en día, con el desarrollo de redes digitales tremendamente versátiles, se está posibilitando la integración de muchas aplicaciones que antes tenían un foco local o puntual respecto a las actividades organizacionales y las conexiones tienden a ser en tiempo real. Por otra parte, estas herramientas que inicialmente servían para procesar y acumular datos, y generar información de apoyo a la toma de decisiones, están siendo crecientemente usadas, en el contexto organizacional postfordista, al servicio del aprendizaje organizacional, la innovación y la gestión del conocimiento. En tal sentido, se las usa destacadamente para: (i) permitir la interacción y el desarrollo de sinergias entre personas dispersas por la organización cuyas experiencias y conocimientos pueden complementarse; 
(ii) acumular y articular digitalmente experiencias de trabajo por la vía de su registro electrónico en el momento en que ocurren; (iii) usar tales registros en la difusión de conocimiento a través de la organización y para el entrenamiento de nuevos miembros; (iv) crear redes de ayuda técnica a los miembros de la organización (cf. Davenport y Prusak, 2000; Hinds y Kiesler, 1999; Constant, Sproull y Kiesler, 1997; Orlikowski, 1995).

En el actual momento de su evolución, como herramienta para la gestión del conocimiento y para el desarrollo de redes dentro de la empresa y con otras organizaciones, la tecnología informática y de la comunicación es el medio tecnológico propio de la nueva fase o paradigma organizacional; es la herramienta tecnológica del postfordismo, que acelera sus procesos de flexibilización productiva, alivianamiento estructural, globalización, aceleración de la innovación, revisión de sus propias prácticas, conectividad con los clientes, desarrollo de alianzas estratégicas, constitución de encadenamientos productivos de extensión global, etc.

En años recientes varias investigaciones han comenzado a explorar la difusión de esta tecnología en Chile y han mostrado su significativa extensión en las empresas del país ${ }^{1}$. Esos resultados son nuestro punto de partida. Lo que aquí nos preguntamos es de qué manera ellas han adoptado esta tecnología. En particular, ¿en qué grado esta adopción corresponde a la perspectiva postfordista de ponerla al servicio del aprendizaje organizacional y gestión del conocimiento? Y, en referencia a esto último, ¿qué factores influyen a favor o en contra de estos usos "avanzados"?

Es decir, más allá de las cantidades de empresas usando una u otra herramienta informática, queremos ver si se están usando sólo de la manera que ha sido convencional en décadas pasadas, para generar datos e información que sirven de apoyo a la toma de decisiones gerencial y para establecer mecanismos de control, o si se están empleando para permitir nuevas prácticas que, por ejemplo, permitan la acumulación e intercambio de experiencia o la constitución de equipos virtuales, prácticas que, típicamente, contribuyen a la gestión de los conocimientos dentro de la empresa y al desarrollo del aprendizaje organizacional. Para buscar respuestas a esto nos basamos en una investigación empírica que hemos estado desarrollando y que aborda dos conjuntos de empresas. Por un lado, una muestra de 168 empresas, con datos provenientes de una encuesta aplicada a sus gerentes. Por otro lado, una muestra de 32 empresas, estudiadas en profundidad, con información proveniente de diferentes fuentes: entrevistas a gerentes, focus groups, entrevistas y encuesta a trabajadores. En ambos

${ }^{1}$ Las más destacadas son las realizadas por la Cámara de Comercio de Santiago (2002, 2003) y por la Subsecretaría de Economía (2002). 
casos, nuestra unidad de estudio está constituida por la empresa mediana y grande, cubriendo diversos rubros tanto de la manufactura como de servicios.

Para indagar en los tipos de uso de las TIC, primero presentaremos un modelo de análisis que ordena las principales variantes en juego. Luego de eso, aludiremos a dos ámbitos de la empresa en que es usada esta tecnología: (1) la comunicación interna y externa; y (2) el control del trabajo $^{2}$. A partir de esta revisión caracterizaremos el uso que las empresas chilenas les están dando a las TIC, contraponiendo usos convencionales, que podríamos llamar "fordistas", con los nuevos usos de carácter postfordista.

Sobre las modalidades de uso de las TIC influyen diversas condiciones socioculturales, tanto de las empresas como de su contexto institucional. No existiría, de tal modo, un curso único hacia el cual vayan convergiendo las empresas y sociedades en el uso de estas tecnologías ${ }^{3}$. Así, en un último punto, nos preguntamos por los factores organizacionales que influyen en las peculiares características que está presentando la digitalización dentro de la empresa, por los factores que están reforzando las pautas de uso que se constata. Al respecto, planteamos varias hipótesis, considerando aspectos tanto técnicos como socioculturales, que luego contrastamos con los datos.

\section{El campo de aplicación de las TIC: un modelo para el análisis}

Las TIC pueden ser empleadas para diferentes fines y su uso puede focalizarse en determinados sectores de la empresa o cubrir la totalidad de ella, o dirigirse hacia fuera de la empresa sirviendo para las conexiones con

${ }^{2}$ Por razones de espacio, hemos dejado fuera las referencias a los software de gestión (tipo ERP), así como las aplicaciones computacionales al proceso productivo. Al respecto, cf. Ramos (2004).

${ }^{3}$ La convergencia o no de los cambios organizacionales, de lo cual son parte las aplicaciones tecnológicas, ha sido materia de amplio debate. Boyer y Hollingsworth (1997), por ejemplo, siguiendo la perspectiva de la Escuela de la Regulación, argumentan que los cambios organizacionales ocurren en estrecha interconexión con los elementos del resto de la sociedad -cultura, instituciones, sistema educativo, forma de Estado, etc. De tal modo se tendría lo que ellos llaman "sistemas sociales de producción", que articulan elementos de las empresas y de su contexto social. Así, sería posible reconocer sistemas de producción muy diferentes que son dominantes en sociedades como la japonesa, alemana, estadounidense o sueca; y algo análogo ocurre, más localmente, en regiones con particulares condiciones institucionales. Esto, que vale para la configuración organizacional en general, es aplicable de modo similar para el uso de las TIC como parte de tales configuraciones organizacionales. Respecto a los moldeamientos socioculturales en el uso que las empresas hacen de las TIC cf. Orlikowski (1999), Orlikowski y Barley (2001), Blom y Melin (2003). 
otras organizaciones. Por otra parte, así como en las primeras fases de desarrollo de la tecnología informática lo que se esperaba de ella eran datos e información, ahora de lo que se habla es de comunicaciones y de conocimiento. Antes de seguir adelante se requiere introducir algunas precisiones respecto a todo esto.

Los diferentes niveles y focos de operatividad de las TIC pueden verse sintetizados y ordenados en el Gráfico $\mathrm{N}^{\circ} 1$, adaptado de Papows (1998). Verticalmente se tienen los diferentes niveles de agregación: individual, grupal, empresa global, extensión organizacional de relaciones con entes relevantes del entorno. Horizontalmente, se va de menor a mayor complejidad, entre datos y reflexividad.

(a) Los datos son meros registros estructurados sobre alguna clase de hechos. Por ejemplo, datos de frecuencias de compra, cantidades de materias primas, ausentismo.

(b) Información es un mensaje comunicado de alguna forma; pueden ser datos analizados, a los cuales se les ha agregado interpretación y sentido, que oriente al receptor. Por ejemplo, información sobre la tendencia de las ventas de una determinada empresa en el último trimestre que ha sido enviada a los diferentes gerentes de ella.

(c) El conocimiento es algo más complejo que la información y mucho más que los datos. El conocimiento involucra pautas integradoras, organizadoras, valorizadoras, que permiten seleccionar y discriminar, sea que operen de manera explícita o tácita. El conocimiento se apoya en experiencia acumulada; remite directa o indirectamente a experiencias pasadas que aparecen, de alguna forma, sedimentadas en el conocimiento ${ }^{4}$. Por ejemplo, el conocimiento que tiene un gerente de comercialización, tras años de experiencia, sobre las formas más adecuadas de negociar con los clientes mayoristas. En las organizaciones, una gran parte del conocimiento, en particular del más específico y valioso para cada organización, se encuentra en forma tácita, no codificada ni de fácil transferencia. Su manejo es, precisamente, uno de los focos de la gestión del conocimiento.

(d) El último nivel de complejidad corresponde a la reflexividad e innovación basada en ella; es la mirada sobre el conocimiento mismo; involucra la revisión de la estructura constitutiva del conocimiento, su generación y transformación. Este puede decirse que es el ámbito en que la gestión del conocimiento opera, o pretende operar. Siguiendo con el mismo ejemplo anterior, sería el caso de un consultor especializado buscando externalizar y registrar los conocimientos tácitos que tiene un gerente de

${ }^{4}$ Véanse mayores explicaciones sobre esta distinción entre datos, información y conocimiento, en Davenport y Prusak (2000). 
GRÁFICO N ${ }^{\circ}$ 1: $\quad$ ÁMBITOS DE DIGITALIZACIÓN DE LA EMPRESA

\begin{tabular}{|c|c|c|c|c|}
\hline $\begin{array}{c}\text { 4. Empresa } \\
\text { extendida } \\
\text { (interconectada } \\
\text { a través del } \\
\text { entorno) }\end{array}$ & $\begin{array}{c}\text { Transacciones } \\
\text { con proveedores } \\
\text { y clientes } \\
\text { (ventas y órdenes } \\
\text { de compra en } \\
\text { línea, etc.) }\end{array}$ & $\begin{array}{c}\text { Comunicaciones } \\
\text { con contrapartes } \\
\text { externas } \\
\text { relevantes } \\
\text { (proveedores, } \\
\text { centros de } \\
\text { investigación, } \\
\text { clientes, etc.) }\end{array}$ & $\begin{array}{c}\text { Gestión y } \\
\text { desarrollo de } \\
\text { relaciones inter- } \\
\text { organizacionales } \\
\text { y con clientes }\end{array}$ & $\begin{array}{c}\text { Gestión y } \\
\text { desarrollo } \\
\text { considerando } \\
\text { al ciberespacio } \\
\text { como espacio } \\
\text { de negocios }\end{array}$ \\
\hline $\begin{array}{l}\text { 3. Empresa } \\
\text { integrada } \\
\text { internamente }\end{array}$ & $\begin{array}{l}\text { Sistemas } \\
\text { de datos y } \\
\text { aplicaciones } \\
\text { a nivel de } \\
\text { empresa }\end{array}$ & $\begin{array}{c}\text { Comunicaciones } \\
\text { a nivel } \\
\text { de empresa } \\
\text { (verticales y } \\
\text { horizontales) } \\
\text { Gestión de } \\
\text { recursos } \\
\text { humanos y } \\
\text { materiales }\end{array}$ & $\begin{array}{c}\text { Gestión del } \\
\text { conocimiento } \\
\text { de la empresa } \\
\text { (desarrollo y } \\
\text { movilización del } \\
\text { capital cognitivo) }\end{array}$ & $\begin{array}{l}\text { Innovación en } \\
\text { procesos de la } \\
\text { empresa } \\
\text { (p. ej. reingeniería } \\
\text { de procesos) }\end{array}$ \\
\hline $\begin{array}{c}\text { 2. Trabajo } \\
\text { grupal virtual }\end{array}$ & $\begin{array}{c}\text { Sistemas de } \\
\text { datos y } \\
\text { aplicaciones } \\
\text { para uso grupal }\end{array}$ & $\begin{array}{c}\text { Comunicaciones } \\
\text { grupales, } \\
\text { cruzando } \\
\text { fronteras } \\
\text { departamentales }\end{array}$ & $\begin{array}{c}\text { Colaboración } \\
\text { en grupos } \\
\text { de trabajo }\end{array}$ & $\begin{array}{c}\text { Innovación en } \\
\text { procesos de } \\
\text { trabajo grupales }\end{array}$ \\
\hline \multirow[t]{2}{*}{$\begin{array}{l}\text { 1. Individuo } \\
\text { interconectado }\end{array}$} & $\begin{array}{c}\text { Acceso, creación, } \\
\text { ingreso y uso } \\
\text { de datos }\end{array}$ & $\begin{array}{c}\text { Acceso, creación } \\
\text { y distribución } \\
\text { de información. } \\
\text { Control de } \\
\text { desempeño }\end{array}$ & $\begin{array}{c}\text { Entrenamiento, } \\
\text { educación, } \\
\text { expertizaje, } \\
\text { socialización }\end{array}$ & $\begin{array}{l}\text { Revisión e } \\
\text { innovación } \\
\text { en prácticas } \\
\text { individuales } \\
\text { de trabajo }\end{array}$ \\
\hline & $\begin{array}{c}\text { A } \\
\text { Datos }\end{array}$ & $\begin{array}{c}\text { B } \\
\text { Información }\end{array}$ & $\begin{array}{c}\text { C } \\
\text { Conoci- } \\
\text { miento }\end{array}$ & $\begin{array}{c}\text { D } \\
\text { Reflexividad } \\
\text { e innovación }\end{array}$ \\
\hline
\end{tabular}

comercialización, a fin de revisar los criterios y modelos mentales de éste, y poder así, en un paso siguiente, difundir a otros integrantes de la organización aquellos elementos, de tal conocimiento, que les puedan ser útiles para sus propias acciones ${ }^{5}$.

La evolución histórica mundial ha sido —viéndola en el Gráfico $\mathrm{N}^{\circ} 1$ - desde el vértice inferior izquierdo, con un desplazamiento tanto vertical como horizontal, avanzando en globalidad y complejidad: desde las bases de datos de los años 50 y 60, a los sistemas de información administrativa y ejecutiva de los 70 y 80 , y luego a las redes de los 90 ,

5 Una discusión más amplia sobre este concepto de "reflexividad" y sus diferentes manifestaciones organizacionales se encuentra en Ramos (2004). 
hasta la gestión del conocimiento, complejización de las redes externas y un desarrollo de la reflexividad que en los últimos años se está haciendo más global y sofisticado. En ese despliegue, tanto los países como las empresas presentan diferentes grados y rutas de avance.

Así, este gráfico provee un útil mapa para analizar el desarrollo de la digitalización de las actividades internas y externas de la organización. En lo que sigue procuraremos tenerlo en cuenta para chequear la situación en las empresas nacionales. No pretendemos, en todo caso, una revisión exhaustiva, sino que, con la información obtenida, cartografiar los relieves y hondonadas más destacados en el espacio digital de nuestras organizaciones.

Apelando a este ordenamiento conceptual podemos redefinir nuestra pregunta inicial: lo que buscamos averiguar es cuánto han transitado las empresas chilenas hacia los usos de las TIC que corresponden a conocimiento y reflexividad organizacional (columnas $\mathrm{C}$ y D). Tales usos son los que consideramos típicamente "avanzados" o "postfordistas", así como, en contraste, los usos referentes a datos e información los consideramos más acordes a una lógica fordista o que, cuando menos, no escapan de ella ${ }^{6}$.

\section{Tecnología informática y comunicación organizacional}

\subsection{Comunicación interna}

Un ámbito fundamental de aplicación de las TIC es la comunicación y la constitución de redes. Con las tecnologías actuales, la forma más sencilla de tal comunicación —el nivel base-, ya sumamente generalizada, es el correo electrónico. Formas más complejas de comunicación e interacción —un segundo nivel- son los programas que permiten y facilitan el trabajo grupal a distancia (groupware). Por esa vía se pueden constituir lugares electrónicos de trabajo, que congregan a empleados que pueden estar dispersos por el mundo. Estas "oficinas virtuales", situadas en el ciberespacio, permiten la interacción y además el almacenamiento de los materiales cognitivos en uso y de los resultados que se vayan obteniendo. Facilita también la constitución u operatividad de "comunidades de práctica" que de otra forma se ven limitadas por constreñimientos espacio-temporales. Un tercer nivel de soluciones tecnológicas para la comunicación organizacional interna son las intranets, que son una derivación organizacional de Internet. (1997).

${ }^{6}$ Sobre el postfordismo y los debates al respecto, cf. Amin (1994), Boyer y Durand 
Una intranet es una red digital diseñada para ser usada por los miembros de una organización, con barreras de entrada para los extraños, y que emplea los protocolos de comunicación de la Internet; es decir, se vale de códigos como el HTML y otros propios de la World Wide Web, usando los típicos browsers, hyperlinks, y tipos de conexión que permiten operar por vía telefónica, de cable, wireless, u otras, e interconectando computadores que poseen cualquiera de los sistemas operativos existentes. Las intranets, además, establecen tecnológicamente sus fronteras externas, así como sus niveles de accesibilidad interna, con passwords y diferentes "perfiles de acceso", de acuerdo a la criticidad y grado de confidencialidad del área de información y conocimiento de la cual se trate. Las fronteras más externas, además, son usualmente protegidas por diferentes barreras "cortafuegos" en prevención de intentos de infiltración o de los ataques de hackers.

Las intranets son una expresión evolutiva de estas tecnologías que permiten englobar a todas las anteriores. Permiten integrar las redes de email, los "equipos virtuales", los diversos registros digitales de la organización que van agregando sus datos, información y conocimientos; como parte de ello pueden establecerse conexiones con datos e información provenientes de los $\mathrm{ERP}^{7}$, de los $\mathrm{CRM}^{8}$, y de otros instrumentos que operan con el formato digital. La intranet facilita, por sus características tecnológicas, el ordenamiento de esa memoria organizacional digital, cada vez más compleja, que se va acumulando, y permite la difusión de su contenido. La intranet puede ser usada como una gran biblioteca multimedial, que crece y se va enriqueciendo día a día, y que puede ser accesada desde cualquier lugar de la organización. De hecho, esa es una concepción bastante generalizada sobre ella, que además es la que prima en nuestras empresas; pero con ella sólo se aprehende una faceta de este complejo "espacio digital" creado por las nuevas tecnologías. La intranet permite crear espacios socioelectrónicos de interacción, a través de los cuales se pueden generar nuevos

${ }^{7}$ El ERP (Enterprise Resource Planning) constituye uno de los paquetes computacionales de gestión más empleados en la actualidad a través del mundo. Son programas computacionales que, aprovechando los conocimientos acumulados internacionalmente sobre una determinada área o proceso de la organización, buscan automatizar y optimizar la administración de las respectivas operaciones. Estos programas típicamente comprenden diversos módulos — de finanzas, administración de personal, desarrollo de productos, manejo de inventarios, distribución, gestión de la cadena de abastecimiento, etc.- , que se pueden adquirir separadamente e ir agregando de acuerdo a las necesidades o a las posibilidades.

${ }^{8}$ El CRM (Customer Relationship Management) es una particular tecnología computacional, para facilitar la atención al cliente, conocerlo mejor, almacenar información respecto a él y la atención que recibe, y poder, sobre esa base, definir acciones más adecuadas. Parte de ello puede ser el establecimiento de un Call Center, sea interno o externo. La tecnología está envuelta en un enfoque de orientación al cliente, buscando establecer lazos más estrechos con él. 
conocimientos, ya sea a través de grupos de proyecto, grupos dedicados al desarrollo de productos, o "comunidades de práctica" con fines más difusos. Permite también establecer redes — con vínculos débiles- de ayuda técnica dentro de la organización, que posibilitan sacar de su marginación a grupos de empleados aislados geográficamente. Es un espacio de comunicación e interacción, vertical y horizontal, ascendente y descendente.

Adicionalmente, una intranet bien constituida es la base para desplegar una extranet que opere efectiva y eficientemente. La extranet es la prolongación de estas comunicaciones e interacciones en formato digital hacia "afuera" de los límites propios, o asumidos normalmente como propios, de la empresa. Involucra la conexión con proveedores, subcontratistas, clientes y otras empresas o entidades organizacionales, y la posibilidad de desarrollar con ellos interacciones análogas a las internas. Este espacio externo de potenciales interrelaciones siempre ha existido, pero con la tecnología informática adquiere una forma concreta, operativa y moldeable con los nuevos medios. Con ello se abre un enorme campo de posibilidades estratégicas, de desarrollo de conocimientos e innovación, de gestación de alianzas y de operaciones internacionales; se facilita, por otra parte, la operatividad y coordinación de encadenamientos productivos y redes diversas entre empresas.

El cabal aprovechamiento de esas posibilidades externas, a través del despliegue de la extranet, descansa, sin embargo, en la adecuada constitución de una intranet. No se puede responder adecuadamente a complejos interlocutores digitalizados, si la digitalización interna no va a la par. Es el conocido principio de la variedad requerida. Una extranet compleja, sin una intranet que la sostenga, que pueda responder a las demandas de los interlocutores externos, sencillamente no va a funcionar bien, y corre el riesgo de crear insatisfacción entre clientes, proveedores y otras entidades externas.

La Tabla $\mathrm{N}^{\circ} 1$ provee información básica sobre la disponibilidad de algunas de estas herramientas en las empresas investigadas.

La tabla muestra cómo se ha extendido el uso de estos medios electrónicos, especialmente en el sector servicios y en las empresas grandes. La disponibilidad de estas herramientas, sin embargo, no da cuenta de la extensión y forma de uso que tienen dentro de las respectivas empresas. La Tabla $\mathrm{N}^{\circ} 2$ agrega esta información. En ella se indica la proporción de empleados que usa algunas de las principales herramientas de las TIC. Las cifras de la tabla muestran la distribución de las empresas según la cobertura de uso que tiene cada tecnología. 
TABLA N ${ }^{\circ} 1: \quad$ TECNOLOGÍA INFORMÁTICA Y COMUNICACIÓN ORGANIZACIONAL INTERNA

(\% de empresas que usan diferentes medios informáticos)

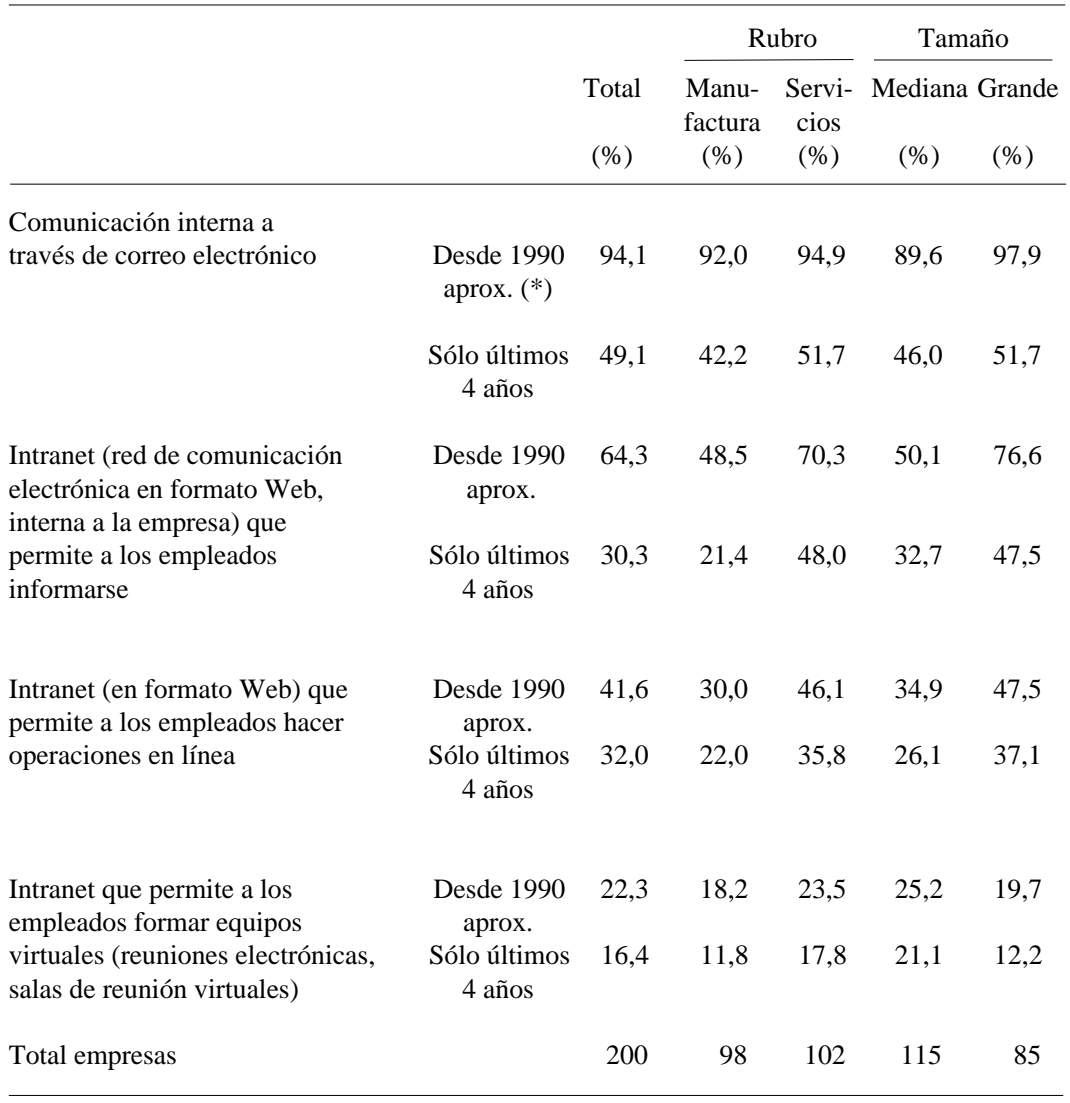

(*) "Desde 1990 aprox." Indica que la práctica respectiva ha sido introducida en la empresa durante el período que va desde aproximadamente 1990 hasta ahora. Esta categoría, por tanto, incluye a la siguiente "sólo en últimos tres años".

No cabe duda que el uso del correo electrónico —el nivel base de conectividad - ya ha pasado a ser la norma en las empresas. El 94,1\% de las empresas se comunica internamente usando este medio. Para ejecutivos y profesionales, y sobre todo en las empresas de servicio, este medio está altamente generalizado. Además, en una cantidad importante de las empresas (38,7\% de ellas) el correo electrónico es utilizado por la mayoría de sus empleados (por más del $60 \%$ de éstos). Por otro lado, puede verse que la 
TABLA N ${ }^{\circ}$ 2: $\quad$ CANTIDAD DE EMPLEADOS CON ACCESO A MEDIOS DE COMUNICACIÓN ELECTRÓNICA DENTRO DE LA EMPRESA

(\% de empresas en cada proporción de uso)

\begin{tabular}{|c|c|c|c|c|c|c|c|c|c|c|}
\hline \multirow{2}{*}{$\begin{array}{l}\text { Cantidad } \\
\text { de } \\
\text { empleados } \\
\text { con } \\
\text { acceso }\end{array}$} & \multicolumn{3}{|c|}{$\begin{array}{l}\text { Uso correo } \\
\text { electrónico } \\
\text { en el trabajo }\end{array}$} & \multirow{2}{*}{$\begin{array}{c}\begin{array}{c}\text { Acceso } \\
\text { a } \\
\text { internet }\end{array} \\
\text { Serv. } \\
(\%)\end{array}$} & \multicolumn{3}{|c|}{$\begin{array}{c}\text { Acceso } \\
\text { a } \\
\text { intranet }\end{array}$} & \multicolumn{3}{|c|}{$\begin{array}{l}\text { Acceso a poner } \\
\text { información } \\
\text { en intranet }\end{array}$} \\
\hline & $\begin{array}{l}\text { Total } \\
(\%)\end{array}$ & $\begin{array}{l}\text { Manu- } \\
\text { fact. } \\
(\%)\end{array}$ & $\begin{array}{l}\text { Serv. } \\
(\%)\end{array}$ & & $\begin{array}{l}\text { Total } \\
(\%)\end{array}$ & $\begin{array}{l}\text { Manu- } \\
\text { fact. } \\
(\%)\end{array}$ & $\begin{array}{l}\text { Serv. } \\
(\%)\end{array}$ & $\begin{array}{l}\text { Total } \\
(\%)\end{array}$ & $\begin{array}{c}\text { Manu- } \\
\text { fact. } \\
(\%)\end{array}$ & $\begin{array}{l}\text { Serv. } \\
(\%)\end{array}$ \\
\hline Ninguno & 6,5 & 11,8 & 0 & 0 & 48,3 & 60,0 & 35,7 & 55,2 & 68,8 & 38,5 \\
\hline $\begin{array}{l}\text { Muy pocos } \\
(1-20 \%)\end{array}$ & 16,1 & 17,6 & 14,3 & 42,9 & 3,4 & 0 & 7,1 & 34,5 & 25,0 & 46,2 \\
\hline $\begin{array}{l}\text { Algunos } \\
(21-40 \%)\end{array}$ & 32,3 & 41,2 & 21,4 & 21,4 & 27,6 & 33,3 & 21,4 & 3,4 & 6,3 & 0 \\
\hline $\begin{array}{l}\text { Alrededor } \\
\text { de la mitad } \\
(41-60 \%)\end{array}$ & 6,5 & 5,9 & 7,1 & 7,1 & 0 & 0 & 0 & 0 & 0 & 0 \\
\hline $\begin{array}{l}\text { La mayoría } \\
(61-80 \%)\end{array}$ & 12,9 & 11,8 & 14,3 & 7,1 & 0 & 0 & 0 & 0 & 0 & 0 \\
\hline $\begin{array}{l}\text { Casi todos } \\
(81-100 \%)\end{array}$ & 25,8 & 11,8 & 42,9 & 21,4 & 20,7 & 6,7 & 35,7 & 6,9 & 0 & 15,4 \\
\hline $\begin{array}{l}\text { Total } \\
\text { empresas }\end{array}$ & 32 & 18 & 14 & 14 & 32 & 18 & 14 & 32 & 18 & 14 \\
\hline
\end{tabular}

incorporación de las empresas al uso de este medio ha crecido notoriamente durante los últimos años, lo cual permite pensar que esa tendencia continuará.

El correo electrónico - así como el resto de herramientas informáticas- tiene efectos graduales y sutiles sobre las prácticas y el conocimiento organizacional. Permite comunicaciones de trabajo relativamente informales, tal como las telefónicas, pero con la peculiaridad de que quedan escritas, siendo la escritura el medio clásico de formalización. Es decir, es una informalidad que se formaliza, que queda registrada. En tal sentido, el email genera la acumulación de memorias organizacionales parciales, locales, que facilitan la revisión de interacciones pasadas, para usarlas como antecedentes, para modificar acciones, para verificar compromisos, etc. Esto ocurre de manera no deliberada, en grados muy diversos; pero, de una $\mathrm{u}$ otra forma, tiene un lento efecto de socialización en las prácticas digitales.

Las comunicaciones por medio de correo electrónico son multidireccionales. De hecho, son sumamente útiles para el desarrollo o reforzamiento de las conexiones organizacionales laterales y, por otra parte, también pueden facilitar y potenciar las relaciones verticales. Con respecto a 
esto último, sin embargo, en las empresas chilenas las comunicaciones ascendentes tienden a ser restringidas y ciñéndose a la línea jerárquica. Aunque la tecnología permita que un empleado envíe emails a los niveles ejecutivos o gerenciales de la empresa, eso no es algo que normalmente ocurra. Hay fuertes barreras culturales que obstaculizan la sola iniciativa de hacerlo. El encargado de la intranet de una organización del sector financiero nos decía que eso sencillamente no ocurre; no está en el conjunto de lo definido como posible en el contexto organizacional de la empresa.

En la mitad de las empresas los gerentes declaraban tener intranet. Cabe precisar, eso sí, que varias de ellas estaban todavía en etapas muy preliminares y rudimentarias de evolución. Su mayor desarrollo se daba en empresas grandes — donde su aporte es más evidente y significativo- y del área de servicios — donde la comunicación es más valorada, por tener culturas habitualmente más orientadas a las personas.

En general, además, el grado de conocimiento sobre las intranets como instrumento de gestión se mostraba bastante limitado. Varios gerentes entrevistados en realidad no tenían claro en qué consiste una intranet ni cuáles pueden ser sus usos y potencialidades. El mayor conocimiento estaba presente en algunas empresas de servicio grandes y en manufactureras que son parte de empresas multinacionales y que, por tanto, están conectadas con intranets internacionales.

El principal uso que, en las empresas nacionales, se les da a las intranets es para proporcionar información a los empleados. En la mayoría de los casos tal información está referida a asuntos administrativos concernientes al personal: licencias médicas, vacaciones, postulaciones, capacitación, finiquitos, asistencia, etc. En algunas empresas había información respecto a materias técnicas del trabajo mismo: instructivos sobre procesos de producción; procedimientos ISO 9000; especificaciones sobre los productos y servicios de la empresa; etc. También se incluían informaciones generales, tales como documentos oficiales de la compañía, noticias sobre la empresa, entrevistas a gerentes, información económica sobre el país, e informaciones sobre actividades sociales o deportivas de los empleados. En algunos casos, los empleados podían hacer ciertas operaciones en línea. En una empresa de servicio $(\mathrm{SG} 20)^{9}$, por ejemplo, un gerente entrevistado contaba que "casi todo el proceso de personal se hace por intranet. La liquidación de sueldo llega por intranet. El bono del sueldo se hace automático a la cuenta corriente y llega un aviso por intranet. Se firma la

${ }^{9}$ Las empresas mencionadas se identifican con una letra que indica el rubro (Servicios o Manufactura), otra que señala el tamaño (Grande o Mediana), y un número para cada una. 
liquidación de sueldo por intranet. Las vacaciones se piden por intranet. Las licencias se piden por intranet".

Indicativos de los contenidos típicos de las intranets nacionales y de su uso, son los resultados registrados en la investigación de Martínez y Pérez (2002: 76) sobre la intranet de un gran banco nacional, el cual ha realizado importantes esfuerzos para lograr su informatización. De la revisión de las visitas a los sitios de la intranet, se reporta que, en el período estudiado — junio del 2002—, los sitios más visitados de la intranet del banco eran: la Central Normativa, con 486 visitas diarias en promedio; Formularios, con 211 visitas diarias; Circulares, con 172; y Noticias, con 122. En el último lugar, con sólo 20 visitas diarias, en una organización con más de 6.000 empleados, estaba un espacio en donde se expresan opiniones libres de los integrantes del banco. Esos son, entonces, los mayores usos de la intranet: poner información útil al alcance de todos y facilitar trámites rutinarios.

En algunas de las empresas vinculadas a multinacionales, la intranet permitía, además, acceder a experiencias — del tipo "mejores prácticas"realizadas en alguna de las unidades de la empresa a través del mundo, sistematizadas para ser empleadas por otras unidades (SG27, MG11).

El acceso de los empleados, por su parte, salvo en una proporción minoritaria de empresas, era sólo para menos de la mitad de ellos. Más significativa, sin embargo, es la falta de interactividad generalizada que se constata en las intranets existentes. Tan sólo en un $41,6 \%$ de las empresas los empleados podían hacer operaciones en línea en la intranet, y la cobertura de tal acceso, en la amplia mayoría de estas empresas, era muy restringido: en general sólo para niveles ejecutivos y unos pocos empleados adicionales. También en cuanto a interactividad, los espacios digitales generados incluían una cantidad muy mínima de oficinas o equipos virtuales para interconectar las acciones de empleados dispersos en la organización, quienes pudieran encontrar provecho en tal conexión para el desarrollo de sus actividades. Asimismo, los programas que permiten comunicación instantánea - tipo ICQ o Messenger (chat) — tenían un uso muy reducido, restringido principalmente a niveles superiores o a determinados profesionales.

También en lo referente al espacio social interno de la empresa, en sus facetas extra o para-laborales — dimensión importante para las dinámicas del clima laboral, para el desarrollo de la cultura organizacional, y para la constitución de redes informales-, las intranets carecían de espacios efectivamente interactivos. A lo más, contaban con algunas mini-encuestas on-line, para ser contestadas por los empleados; o disponían de lugares 
para poner noticias sociales y deportivas, como una especie de diario mural.

En resumen, la intranet se usa bastante para poner información organizacional útil al alcance de los integrantes de la empresa y se aprovecha como medio de comunicación institucional (comunicación vertical descendente). Es muy débil, en contraste, su empleo como herramienta de trabajo que permita la interacción ${ }^{10}$. En la actualidad, el desarrollo de equipos virtuales y el trabajo en lugares electrónicos de reunión, actividades con potencialidades para la generación y transmisión de conocimientos, tienen exiguas manifestaciones en las empresas. La noción misma de la interacción y trabajo en lugares electrónicos no parece bien comprendida, mucho menos, por tanto, se le atribuye utilidad. Algo semejante nos ha tocado ver en otras empresas, consideradas de punta, en sectores de la minería y del marketing. Estos desarrollos sociotecnológicos no han entrado en las culturas corporativas de nuestro país. De tal modo, las celdillas $2 \mathrm{C}$ y $2 \mathrm{D}$ de nuestro gráfico están prácticamente inhabitadas por las empresas chilenas.

\subsection{Conexiones electrónicas externas}

La tecnología informática, como ya hemos dicho, potencia las conexiones entre empresas, posibilita formas complejas de coordinación interorganizacional, y permite conectar la empresa con sus clientes. El estudio, antes citado, del Ministerio de Economía (2002), provee datos, con representatividad a nivel nacional, que permiten visualizar el estado general de las conexiones electrónicas externas. Los resultados pertinentes están en la Tabla $\mathrm{N}^{0} 3^{11}$.

La lectura de estos datos permite sacar algunas conclusiones:

(1) Las empresas chilenas ya cuentan con un tejido digital externo de importancia, al menos en cuanto a la cantidad de lazos electrónicos establecidos. En cuanto a los aspectos cualitativos de tales lazos, sin embargo, nuestra investigación indica que su uso fundamental es para el intercambio de información, y poco para el desarrollo del conocimiento, reflexividad o innovación.

(2) Las conexiones más generalizadas, que demuestran ser fructíferas, no son entre empresas, sino que entre éstas con bancos y entidades

10 También es reducido su empleo para generar espacios de encuentro social.

11 Nuestros resultados coinciden, a grandes líneas, con los del Ministerio de Economía. Por eso, preferimos registrar estos últimos, dados el tamaño y representatividad de la muestra que emplean. 
TABLA N ${ }^{\circ}$ 3: CONEXIONES ELECTRÓNICAS EXTERNAS DE LAS EMPRESAS, EN MUESTRA NACIONAL, DE TODOS LOS RUBROS DE ACTIVIDAD ECONÓMICA NO AGRÍCOLA

(\% de empresas por tipo de conexión o uso)

\begin{tabular}{lccc}
\hline & & \multicolumn{2}{c}{$\begin{array}{c}\text { Tamaño } \\
\text { (en miles de UF) }\end{array}$} \\
\cline { 3 - 4 } & Total $(*)$ & $\begin{array}{c}\text { Medianas } \\
(50-100)\end{array}$ & $\begin{array}{c}\text { Grandes } \\
(100-300) \\
\end{array}$ \\
& $(\%)$ & $(\%)$ & $(\%)$ \\
\hline Página Web & 14,0 & 36,6 & 52,6 \\
Conexión con proveedores & 34,8 & 40,8 & 46,0 \\
Se informa de precios y ofertas & 61,7 & 50,2 & 60,7 \\
Cotiza insumos y/o servicios & 55,2 & 59,8 & 66,6 \\
Compra insumos y/o servicios & 27,8 & 34,3 & 30,5 \\
Se informa de estado del pedido & 13,0 & 15,4 & 14,5 \\
Conexión con banco & 69,7 & 79,2 & 84,5 \\
Conexión con servicio público & 66,9 & 72,8 & 79,7 \\
Conexión con clientes & 30,2 & 35,0 & 42,7 \\
Venta de productos y/o servicios & 18,3 & 20,3 & 17,9 \\
Total de empresas & $(3.134)$ & $(643)$ & $(550)$ \\
\hline
\end{tabular}

(*) Nota: Este total incluye también los resultados de empresas pequeñas (2.4-25 miles de UF) y pequeñas-medianas (25-50 miles de UF).

Fuente: Subsecretaría de Economía (2002).

estatales. Cabe destacar que el Estado chileno ha sostenido una clara política de implementar esta tecnología en sus reparticiones y de fomentar que las empresas se conecten con el Estado por medios electrónicos. Los datos de esta encuesta señalan que tal política estaría siendo efectiva.

(3) Una cantidad importante de empresas - superior al $40 \%$ en el caso de las medianas y grandes - mantiene lazos electrónicos con sus proveedores. Dado que estas prácticas tienden a fortalecerse con el uso, cabe prever que esa cifra seguirá incrementándose. Los límites sólo estarán dados por la menor conectividad y más lenta incorporación de elementos computacionales en las empresas más pequeñas, dificultando la conexión digital con ellas. Pero la creciente reducción de costos de la tecnología informática haría prever que esas dificultades se irán pronto reduciendo ${ }^{12}$.

${ }^{12}$ Según estimaciones, el ahorro en transacciones como las bancarias cuando ocurren a través de las redes digitales es altamente significativo, del orden del $89 \%$; el ahorro en las ventas entre empresas, por su parte, está alrededor del 10-20\%, según los sectores económicos de que se trate (OIT, 2002:89). 
(4) Ya se ha instaurado, aunque no generalizado, la conexión digital con los clientes, como lo demuestra que el 30,2\% del total de empresas mantenga algún tipo de comunicación electrónica con ellos. En el caso de las empresas medianas y grandes es, además, significativo el número de las que cuentan con página Web. Nuevamente, hay que decir que si bien existen las conexiones, éstas todavía tienen muchas limitaciones y son, por lo general, muy poco sofisticadas - en muchos casos no incluyen más que datos de la empresa y conexiones de email.

(5) Todavía prima el uso de la red electrónica externa para informarse antes que para llevar a cabo transacciones económicas. Mientras más de la mitad de las empresas usa estas conexiones para informarse sobre productos y servicios, y para cotizar precios, sólo alrededor de un tercio las usa para comprar; y no más del $20 \%$ las usa para vender ${ }^{13}$.

En resumen, no cabe duda que las conexiones digitales inter-organizacionales y con clientes se han ido extendiendo. Su utilización, no obstante, ha estado focalizada en la obtención de información, en la canalización de mensajes, sin dar forma a procesos colaborativos. No ha estado tal utilización al servicio de la gestión del conocimiento y no se aprecia que estas interacciones digitales se usen ni se conciban como instancias para el aprendizaje organizacional (hay, así, desarrollos notorios en las celdillas 4A y 4B; algo en 4C; y casi nada en 4D).

\section{Autonomía y control en el trabajo}

En general, durante la última década, en las empresas chilenas, ha aumentado gradualmente la descentralización y se ha ido concediendo mayor autonomía a los trabajadores. Sin embargo, en general es una autonomía limitada ${ }^{14} \mathrm{y}$, en contraposición, el desarrollo de los mecanismos de control, en particular los basados en la tecnología informática, alcanzan una mayor extensión. Esto se puede apreciar en la Tabla $N^{\circ} 4$.

${ }^{13}$ De cualquier forma, el porcentaje de transacciones entre empresas que son realizadas en Internet corresponde, en Chile, al 2,0\% del total de transacciones. En EE.UU. es el 14,0\%; en Alemania el 8,1\%; en Suecia el 7,3\%; en Italia el 6,3\%; en Japón el 5,8\% (Cámara de Comercio de Santiago, 2002:54). El comercio electrónico está sólo comenzando en Chile; pero no se encuentra tan atrás de los países más avanzados.

${ }^{14}$ Mayores informaciones y análisis sobre los cambios ocurridos en cuanto a la autonomía y organización del trabajo, basados en resultados de una encuesta y entrevistas a trabajadores, se encuentran en Ramos (2003). 
TABLA N ${ }^{\circ} 4$ : CAMBIOS EN AUTONOMÍA Y CONTROL EN EL TRABAJO

(\% de empresas que aplica cada medida)

\begin{tabular}{|c|c|c|c|c|c|c|}
\hline \multirow[t]{2}{*}{ Aplicación de medidas } & & \multirow[b]{2}{*}{$\begin{array}{l}\text { Total } \\
(\%)\end{array}$} & \multicolumn{2}{|c|}{ Rubro } & \multicolumn{2}{|c|}{ Tamaño } \\
\hline & & & $\begin{array}{l}\text { Manu- } \\
\text { factura } \\
(\%)\end{array}$ & $\begin{array}{l}\text { Servi- } \\
\text { cios } \\
(\%)\end{array}$ & $\begin{array}{c}\text { Mediana } \\
\text { (\%) }\end{array}$ & $\begin{array}{c}\text { Grande } \\
(\%)\end{array}$ \\
\hline \multirow{2}{*}{$\begin{array}{l}\text { Asignación de mayor } \\
\text { poder de decisión a los } \\
\text { trabajadores respecto a } \\
\text { su trabajo }\end{array}$} & $\begin{array}{l}\text { Desde } 1990 \\
\text { aprox. }\end{array}$ & 31,0 & 35,3 & 25,0 & 40,0 & 21,4 \\
\hline & $\begin{array}{l}\text { Sólo últimos } \\
4 \text { años }\end{array}$ & 13,8 & 23,5 & 0 & 13,3 & 14,3 \\
\hline \multirow{2}{*}{$\begin{array}{l}\text { Sistemas de control } \\
\text { computarizado del } \\
\text { trabajo }\end{array}$} & $\begin{array}{c}\text { Desde } 1990 \\
\text { aprox. }\end{array}$ & 40,0 & 31,3 & 50,0 & 40,0 & 40,0 \\
\hline & $\begin{array}{l}\text { Sólo últimos } \\
\quad 4 \text { años }\end{array}$ & 20,0 & 6,3 & 35,7 & 26,7 & 13,3 \\
\hline
\end{tabular}

La descentralización, como vía necesaria para conseguir mayor rapidez en la toma de decisiones y una mayor adecuación de ella a las realidades locales, habría alcanzado fundamentalmente hasta los niveles de jefaturas y mandos medios. Las dificultades para bajar más la toma de decisiones parecen estar, de modo importante asociadas a factores culturales y psicosociales: culturas corporativas tradicionales y jerárquicas, modelos mentales de los gerentes y jefes que no valoran lo suficiente la iniciativa de los empleados, falta de experiencia de participación, etc.

Paralelamente a ese avance limitado de la autonomía, ha ocurrido, por la vía de la tecnología informática, un aumento del control externo sobre las actividades laborales, lo cual se presenta en el 40,0\% de las empresas, y está más extendido en las de servicio (ocurre en el $50 \%$ de ellas).

Esta ha sido una de las tendencias mundiales, asociadas al desarrollo de las TIC. Así, por ejemplo, de acuerdo a una encuesta aplicada en el 2000, a 2.100 empresas de EE.UU., casi el $75 \%$ de ellas registraban y revisaban las comunicaciones y actividades del personal y esto había estado aumentando (American Management Association, 2000) ${ }^{15}$. Un mayor detalle de los resultados de tal estudio se aprecian en la Tabla $\mathrm{N}^{\circ} 5$.

La vigilancia electrónica de las actividades realizadas por los trabajadores se ha extendido, y la tendencia es creciente, como revelan los datos de la Tabla $\mathrm{N}^{\circ}$ 5. Esto también se manifiesta en Chile, con ese $40 \%$ de

${ }^{15}$ Según lo reportado en informe mundial de la OIT (2002:313, 314). 
TABLA N ${ }^{\circ}$ 5: $\quad$ VIGILANCIA ELECTRÓNICA DEL PERSONAL EN EE.UU., 1997-2000

(\% de empresas que aplica cada medida)

\begin{tabular}{|c|c|c|c|c|}
\hline Medidas de control & 1997 & 1998 & 1999 & 2000 \\
\hline Lectura y examen de archivos computacionales & 13,7 & 19,6 & 21,4 & 30,8 \\
\hline Lectura y examen de mensajes de correo electrónico & 14,9 & 20,2 & 27,0 & $38,1^{*}$ \\
\hline Grabación en video de las actividades de trabajo & 15,7 & 15,6 & 16,1 & 14,6 \\
\hline $\begin{array}{l}\text { Número de llamadas telefónicas y tiempo invertido } \\
\text { en ellas }\end{array}$ & 34,4 & 40,2 & 38,6 & 44,0 \\
\hline $\begin{array}{l}\text { Utilización de los computadores (tiempo } \\
\text { empleado y número de digitaciones en el teclado) }\end{array}$ & 16,1 & 15,9 & 15,2 & 19,4 \\
\hline Videovigilancia con fines de seguridad & 33,7 & 32,7 & 32,8 & 35,3 \\
\hline
\end{tabular}
2003).

* En 2003 esta cifra había llegado al 52\% (American Management Association,

Fuente: American Management Association (2000).

empresas que aplica estos procedimientos, de los cuales la mitad ha comenzado a hacerlo en los últimos tres años.

El registro digital de las actividades da pie para el control. El gerente de una empresa de servicio (SG20), explicaba el manejo que tenían de la información. Según él, contaban con un "espectacular" nivel de información de la gestión por cliente, de los mejores a nivel latinoamericano. Eso les permite saber "exactamente" cómo es la gestión y la rentabilidad por cada cliente, y cuántos y cuáles productos está ocupando éste. Con eso resulta fácil hacer seguimientos por ejecutivo de cuentas, por sucursal, o por cualquier unidad que interese. Así por ejemplo, decía, "tú sabes exactamente el comportamiento de cada ejecutivo de cuentas". El registro electrónico que se lleva permite la evaluación y control del desempeño de los empleados, sobre la base de información que puede considerarse notoriamente más "objetiva" que otras posibles.

En tal sentido, este uso de la información digital permite un efectivo monitoreo de la actividad que se realiza en la organización, y permite proveer una retroalimentación valiosa a los integrantes y unidades de la empresa. En la medida que lo registrado refleje fielmente las actividades laborales centrales, estos sistemas además de ser un aporte para la organización, también pueden ser valorados por los empleados.

En algunos casos, sin embargo, tales sistemas de monitoreo son percibidos por los trabajadores como mera vía para "pillarlos en falta". En una empresa (SM24) los empleados, en una discusión de focus group, 
coincidían en la impresión de sentirse vigilados constantemente. Con el nuevo sistema computacional, decían: "uno queda absolutamente identificado", si es que, por ejemplo, factura algo mal. Por otra parte, decía otro, "tenemos cámaras por todos lados [...], hasta en el casino". Incluso varios estaban convencidos de que "los teléfonos están intervenidos". "Muchas veces - explicaba uno - te pinchan la línea. Tú a veces estái hablando y sientes cuando te están escuchando". En el año 2000, en el 11,5\% de las empresas norteamericanas encuestadas, según el estudio antes mencionado, las conversaciones telefónicas de los empleados eran escuchadas y controladas. Así, lo que los empleados citados reportan respecto a la vigilancia telefónica no resulta tan extraño. De cualquier manera, sea efectiva o no tal intervención telefónica, lo destacable es la intensidad que ahí alcanzaba la sensación de sentirse vigilados electrónicamente, y la inquietud o temor derivados. En otra empresa, del ámbito de las telecomunicaciones (SG31), tenían complejos sistemas de control computarizado del trabajo. Aquí, un gerente decía, con respecto a las operadoras que manejan bases de datos, que "ellas ni siquiera se percatan, y sabemos en detalle qué es lo que hacen [...], cuántas llamadas hicieron en el día [...] todo eso lo controlamos". Probablemente, algunas no se percaten, como piensa este gerente; pero otras sí lo harán. Pero es sobre todo el tipo de uso que le dé la gerencia a la información que se obtiene lo que genera o no un clima de vigilancia, un clima en que los trabajadores se muestran sensibles, negativamente, al tema; o un clima favorable o en que los trabajadores no demuestran percatarse del control computacional. Tal uso, a su vez, se relaciona con el marco cultural y estilos de gestión en que tales prácticas se insertan.

Son variadas las actividades sujetas a monitoreo informático. En algunas compañías se tiene el registro automático de la presencia del empleado, y sus ingresos y salidas. El control del uso de los computadores también ocurre en algunos casos, aunque todavía es poco sofisticado; así, frente a los usos no laborales que los trabajadores hacen de Internet en su puesto de trabajo, muchas empresas, en lugar de apelar a algún software de monitoreo, han "resuelto" tal problema eliminando, simplemente, el acceso a Internet para los empleados.

En contraste, en una empresa del sector de las telecomunicaciones (SG21) se daba un uso más complejo de esta tecnología, proveyéndoles a los empleados una retroalimentación en línea sobre el servicio que están prestando, avisándoles del tiempo que llevan atendiendo a sus clientes, informándoles de los clientes que están esperando y de sus características, y enviándoles señales de atención cuándo ese tiempo se extiende más allá de los rangos que han sido predeterminados (centralmente). Tales señales 
son además recibidas por quien supervisa a tales empleados, quien acude cuando tales demoras se siguen prolongando o se reiteran. Esta herramienta es, así, ambivalente para los empleados. Por una parte los apoya en su labor, pero por otra los presiona y "denuncia" si no hacen caso. Esto queda reflejado en los comentarios de los empleados entrevistados. Una contaba: "Un día atendí a cuarenta y tantos clientes y me dije 'genial, ¿cómo lo hice?'. Te vas viendo tu tiempo. [En un determinado momento] ya sabes que llevas más de los quince minutos permitidos; estás en rojo [...] y uno tiene que acelerar. A veces se da que el cliente se quiere poner a conversar y uno tiene que darle el corte definitivo, o sea, no siendo pesada, pero [...]". Antes, "ya terminabai de atender al cliente, [y entonces] o que te ibai al baño, o que te ibai a donde tu compañera al otro lado. Ahora no, ahora te ves obligada a cerrar la atención. Y te llaman al tiro a otro [cliente]. Entonces se da una atención más rápida". Otra empleada estimaba que ese sistema "es una herramienta de presión horrorosa"; y explicaba: "en 15 minutos tenís que arreglarle la cuenta al cliente, tenís que ver el problema que tiene el cliente, le tenís que vender un producto al cliente, tenís que cambiar el equipo al cliente, en 15 minutos, o sea, tú comprenderás que [...] Y si te demoras más de esos 15 minutos viene la supervisora y pregunta qué es lo que pasa, por qué tú estás en rojo. Entonces es como una alarma que aparece en el computador".

En conclusión, entonces, así como, por un lado, las TIC son objeto de escaso uso en materia de desarrollo de conocimiento, aprendizaje organizacional e innovación, por otro, su empleo para el control del trabajo ha aumentado. Esto involucra un tipo de empleo básicamente unilateral y vertical, acorde con estilos tradicionales — "fordistas"- de gestión, el cual, si no es manejado adecuadamente, tiende a deteriorar la confianza y el clima laboral.

\section{Estado general de la aplicación de las TIC en las empresas}

Considerando las informaciones empíricas precedentes, si volvemos ahora al gráfico pensado para "mapear" el grado de digitalización interna de la organización, es decir para representar el grado de despliegue de la aplicación de las TIC, la situación en las empresas chilenas estudiadas podría reflejarse tal como aparece en el gráfico a continuación. En él, la cantidad de "+" refleja el grado de aplicación y consolidación en una escala entre 0 y 7 grados. La ausencia del signo "+" o la presencia de solamente una "+" indica ausencia de digitalización en ese aspecto o desarrollos todavía muy embrionarios y débiles. 
GRÁFICO N ${ }^{\circ}$ 2: $\quad$ GRADOS DE APLICACIÓN DE LA TECNOLOGÍA INFORMÁTICA A LA COMUNICACIÓN E INTERACCIÓN ORGANIZACIONAL EN LAS EMPRESAS CHILENAS

\begin{tabular}{|c|c|c|c|c|}
\hline $\begin{array}{l}\text { 4. Empresa } \\
\text { extendida } \\
\text { (interconectada } \\
\text { a través del } \\
\text { entorno) }\end{array}$ & $\begin{array}{c}\text { Transacciones } \\
\text { con proveedores } \\
\text { y clientes } \\
\text { (ventas y órdenes } \\
\text { de compra en } \\
\text { línea, etc.) } \\
\\
++\end{array}$ & $\begin{array}{c}\text { Comunicaciones } \\
\text { con contrapartes } \\
\text { externas } \\
\text { relevantes } \\
\text { (proveedores, } \\
\text { centros de } \\
\text { investigación, } \\
\text { clientes, etc.) } \\
++\end{array}$ & $\begin{array}{c}\text { Gestión y } \\
\text { desarrollo de } \\
\text { relaciones inter- } \\
\text { organizacionales } \\
\text { y con clientes }\end{array}$ & $\begin{array}{c}\text { Gestión y } \\
\text { desarrollo } \\
\text { considerando al } \\
\text { ciberespacio } \\
\text { como espacio } \\
\text { de negocios }\end{array}$ \\
\hline $\begin{array}{l}\text { 3. Empresa } \\
\text { integrada } \\
\text { internamente }\end{array}$ & $\begin{array}{l}\text { Sistemas de } \\
\text { datos y } \\
\text { aplicaciones a } \\
\text { nivel de } \\
\text { empresa }\end{array}$ & $\begin{array}{c}\text { Comunicaciones } \\
\text { a nivel de } \\
\text { empresa } \\
\text { (verticales y } \\
\text { horizontales). } \\
\text { Gestión de } \\
\text { recursos humanos } \\
\text { y materiales } \\
+++++\end{array}$ & $\begin{array}{l}\text { Gestión del } \\
\text { conocimiento } \\
\text { de la empresa } \\
\text { (desarrollo y } \\
\text { movilización } \\
\text { del capital } \\
\text { cognitivo) }\end{array}$ & $\begin{array}{c}\text { Innovación } \\
\text { en procesos } \\
\text { de la empresa } \\
\text { (p. ej. reingeniería } \\
\text { de procesos) }\end{array}$ \\
\hline $\begin{array}{c}\text { 2. Trabajo } \\
\text { grupal virtual }\end{array}$ & $\begin{array}{c}\text { Sistemas de datos } \\
\text { y aplicaciones } \\
\text { para uso grupal } \\
\\
++++ \\
\end{array}$ & $\begin{array}{c}\text { Comunicaciones } \\
\text { grupales, } \\
\text { cruzando fronteras } \\
\text { departamentales } \\
+++ \\
\end{array}$ & $\begin{array}{l}\text { Colaboración en } \\
\text { grupos de trabajo }\end{array}$ & $\begin{array}{c}\text { Innovación } \\
\text { en procesos de } \\
\text { trabajo grupales }\end{array}$ \\
\hline \multirow[t]{2}{*}{$\begin{array}{c}\text { 1. Individuo } \\
\text { interconectado }\end{array}$} & $\begin{array}{c}\text { Acceso, creación, } \\
\text { ingreso y uso de } \\
\text { datos } \\
\\
+++++\end{array}$ & $\begin{array}{c}\text { Acceso, creación } \\
\text { y distribución } \\
\text { de información. } \\
\text { Control de } \\
\text { desempeño } \\
++++\end{array}$ & $\begin{array}{l}\text { Entrenamiento, } \\
\text { educación, } \\
\text { expertizaje, } \\
\text { socialización }\end{array}$ & $\begin{array}{l}\text { Revisión e } \\
\text { innovación } \\
\text { en prácticas } \\
\text { individuales } \\
\text { de trabajo }\end{array}$ \\
\hline & $\begin{array}{c}\text { A } \\
\text { Datos }\end{array}$ & $\begin{array}{c}\text { B } \\
\text { Información }\end{array}$ & $\begin{array}{c}\text { C } \\
\text { Conoci- } \\
\text { miento }\end{array}$ & $\begin{array}{c}\text { D } \\
\text { Reflexividad } \\
\text { e innovación }\end{array}$ \\
\hline
\end{tabular}

Es indudable el avance logrado, tanto interna como externamente ${ }^{16}$. Existe, además, conciencia sobre las posibilidades contenidas en las herramientas informáticas para el desarrollo de la empresa. Sin embargo, aún no

16 Cabe mencionar y destacar que los resultados de dos investigaciones recientes (Cámara de Comercio de Santiago, 2002, y Subsecretaría de Economía, 2002), muestran que el nivel de "capacidad de absorción de las tecnologías informáticas y de la comunicación” y la conectividad de las empresas chilenas está entre los más altos de América Latina. El Centro de Estudios de la Economía Digital, de la Cámara de Comercio de Santiago, pone a Chile en el primer lugar, marcadamente por sobre Argentina, Costa Rica, Colombia, Brasil, México y Perú. El índice de "capacidad de absorción de TIC" para Chile es de 45.3, mientras para Argentina es de 38.0, para Brasil 28.2 y para México es 23.4 (Cámara de Comercio de Santiago, 2002:23). Por otro lado, a nivel mundial, Chile se encuentra en una posición que, aunque lejana de los países líderes, es avanzada respecto a países de características similares, y es de los que muestran un acelerado ritmo de avance. Las comparaciones realizadas por la Cámara de Comercio (CCS) colocan a Chile en un lugar intermedio entre los países líderes en materia de TIC y los rezagados, en la condición de "seguidor potencial" (CCS, 2002:22). 
se han dado pasos significativos hacia la concepción y uso de estas tecnologías como medios para la gestión del conocimiento y para la reflexividad organizacional. En esto, según constatamos en las entrevistas realizadas, no existe aún conocimiento suficiente sobre su utilidad y, menos, sobre los caminos prácticos a seguir para su implementación. Así, los avances siguen dándose en las columnas referidas a "datos" e "información" y es marcada la debilidad en materia de "conocimiento" y de "reflexividad e innovación". Por otra parte, hay un llamativo vacío en la aplicación informática al servicio del trabajo grupal. De todo esto se deriva que buena parte del potencial de estas tecnologías, en materia de aprendizaje, innovación y mejoramiento organizacional, aún no sea aprovechado por las empresas nacionales.

Lo que cabría, entonces, preguntarse es por los factores que llevan a la situación actual y por los caminos para salir de ella, hacia un uso más provechoso de las TIC. A esto apunta la sección siguiente.

\section{Factores que condicionan la digitalización de las comunicaciones en las empresas}

¿A qué se debe este uso limitado y desbalanceado de las TIC, que constatamos en las empresas chilenas? ¿Qué factores explican el mayor o menor uso de esta tecnología? La respuesta más habitual es que se trata de un asunto fundamentalmente de recursos. Por eso, se espera encontrar que las empresas más grandes y con mejores condiciones económicas aplican más las TIC y lo hacen para fines más sofisticados.

Indudablemente que ese es un factor, pero los conocimientos acumulados en la materia nos llevan a afirmar que además hay otros factores, particularmente de índole sociocultural, que pueden ser tanto o más decisivos para explicar la variedad de situaciones que se encuentra en materia de uso de las TIC.

\subsection{Hipótesis}

El empleo de las TIC para la generación de conocimiento y fomento de prácticas interactivas (como los equipos virtuales) requiere que en la empresa se hayan legitimado las relaciones de colaboración y participación de los empleados en los procesos técnicos. Las TIC por sí solas no proveen gestión del conocimiento ni aprendizaje organizacional; estos procesos involucran la existencia en la organización de actividades y relaciones entre 
las personas orientadas a compartir, revisar y desarrollar el conocimiento tácito existente, el cual, habitualmente no es fácil de codificar y hacer transportable (McDermott, 1999). Se requiere que existan redes, formales e informales, para hacer posible la conexión, generación y transferencia de conocimientos (Soo et al., 2002). Todo esto implica atender al plano de la realidad social y cultural de la empresa. Se necesita, de tal modo, que exista una cultura organizacional que promueva la participación de los trabajadores en la revisión y mejoramiento de los procesos de trabajo. Nuestra hipótesis al respecto, que procuramos chequear empíricamente, por tanto, es que la existencia en la empresa de culturas participativas y reflexivas influye en un mayor empleo de las TIC para las comunicaciones y desarrollo del conocimiento interno. Más específicamente, consideraremos, como expresión de tales culturas, la existencia de prácticas efectivas de participación y colaboración de los empleados, dado que tales manifestaciones prácticas son un buen indicador, válido y confiable, de las orientaciones culturales, por sí mismas más elusivas (Hipótesis 1).

Tales culturas participativas, a su vez, son más frecuentes en países de capitalismo avanzado. En ellos alcanza una mayor difusión el uso de prácticas de reflexividad y aprendizaje organizacional ${ }^{17}$. En términos más amplios, consideramos que tales desarrollos en las empresas de esos países son parte de procesos más generales de "modernización reflexiva" que han estado tomando lugar en tales sociedades (Beck, Giddens y Lash, 1997). Por tanto, podemos pensar que en aquellas empresas en las cuales parte de su propiedad está en manos extranjeras, este hecho podría involucrar la influencia de tales culturas corporativas extranjeras estimulando, en las respectivas empresas nacionales, el desarrollo de estilos más participativos y, derivadamente, de un mayor uso de las TIC para la comunicación interna (Hipótesis 2).

El grado de complejidad y dinamismo del entorno específico en que se mueven las empresas es otro factor que estimula un mayor uso de las TIC. Aquellas empresas en entornos más complejos, estarán sujetas a una mayor presión para establecer nuevos y mejores mecanismos de comunicación, tanto interna como externa, y por ende tendrán una mayor propensión a valerse de los medios digitales que facilitan tales comunicaciones (Hipótesis 3). Esta constituiría una explicación "técnica" del mayor empleo de las TIC. Después de la explicación económica, ésta es la segunda más recurrida por parte de los gerentes y en las publicaciones de negocios. La

${ }^{17}$ Cf. por ejemplo, respecto a su difusión en EE.UU., a Lawler, Mohrman y Ledford (1998), Appelbaum y Batt (1994); respecto a Japón, Kenney y Florida (1993). 
conveniencia técnica y la búsqueda de eficiencia impulsarían a las empresas a ir usando las técnicas y procedimientos que tienen mayor potencialidad y así se iría generando una creciente convergencia en los usos que les dan las empresas a estas tecnologías. Nuestro planteamiento al respecto es que, aún reconociendo la influencia de factores técnicos tales como de los económicos, éstos no bastan, y no son suficientes para explicar la variedad de usos de las TIC.

La inclusión en redes es otro factor que incide sobre la digitalización en la empresa. Ha sido ampliamente planteada la asociación entre el desarrollo de redes interempresas y el empleo de la TIC (Castells, 1996; Castells, 2001). En Chile, sin embargo, las redes de subcontratación son peculiarmente débiles y poco desarrolladas y otras modalidades de redes, como las alianzas estratégicas, son todavía un fenómeno incipiente. En contraste, las redes que sí son sólidas, importantes e influyentes, son las redes de propiedad (Ramos, 2004). Así, en el caso chileno, la inclusión en tales redes de propiedad influiría en el desarrollo de la digitalización de las redes externas de la empresa y, con ello, en la digitalización global de la empresa (Hipótesis 4).

Tendríamos, por tanto, cinco hipótesis a chequear empíricamente:

H1: A mayor cultura reflexivo-participativa mayor digitalización interna.

H2: A mayor conexión de propiedad con empresas de países de capitalismo avanzado, mayor digitalización interna y total.

H3: A mayor complejidad del entorno específico de la empresa mayor digitalización interna y total.

H4: La participación en vínculos de propiedad con otras empresas influirá en una mayor digitalización total.

H5: A mayor tamaño de la empresa, mayor digitalización interna y total.

Para los análisis, emplearemos las dos muestras de nuestro estudio. Ambas incluyen solamente empresas medianas y grandes, que son las que más prontamente cabe esperar que incorporen los avances y mejoramientos técnicos y organizacionales. Llamaremos "metropolitana" a la muestra del estudio en profundidad, que incluye 32 empresas de la Región Metropolitana, y "nacional" a la de 168 empresas correspondientes a todo el país. La muestra metropolitana contiene información que permite generar variables a partir de las respuestas de los trabajadores y, con ello, dar mayor solidez a los resultados. 


\subsection{Variable dependiente}

La variable que buscamos explicar es la digitalización de los procesos de comunicación de la empresa. La hemos separado en dos: (1) digitalización interna, construida con indicadores de usos comunicativos internos (cuatro en muestra metropolitana y tres en muestra nacional; con Alpha de Cronbach de 0.62 y 0.76 , respectivamente) que reflejan usos para la comunicación dentro de la empresa, incluyendo usos interactivos, avanzados, y (2) digitalización total, que incluye la comunicación tanto interna como externa (medida a través de seis indicadores en muestra metropolitana y ocho en muestra nacional, con Alpha de 0.70 y 0.75 , respectivamente). Los valores del Alpha de Cronbach, para medir confiabilidad, muestran una adecuada consistencia interna en la construcción de estos índices.

\subsection{Variables independientes}

La variable participación / reflexividad está medida en dos formas diferentes, pero complementarias, en ambas bases. En la base nacional, en que los informantes son solamente gerentes se mide la existencia de formas institucionales que permitan la participación activa y la revisión de las prácticas de trabajo, por parte de los empleados. Se incluyen cinco indicadores que buscan reflejar el grado de estructuración y cobertura de tales formas organizativas (Alpha $=0.70)$. En el caso de la muestra metropolitana, la variable se mide a través de las respuestas que los propios trabajadores dan a tres preguntas, integradas luego en un índice, sobre la existencia de prácticas para revisar el proceso de trabajo y colaborar en su mejoramiento, y su participación efectiva en ellas. Las respuestas de los trabajadores son atribuidas, como variable agregativa, a cada establecimiento sirviendo para caracterizar la presencia en él de una cultura participativoreflexiva (Alpha $=0.77)$.

La participación del capital extranjero, correspondiente a países de capitalismo avanzado, en la base nacional está medida como su porcentaje de participación en la propiedad de la empresa y en la metropolitana como variable dummy (presencia o ausencia de tal capital).

La complejidad del entorno específico está operacionalizada a través de tres indicadores sobre la intensidad de la competencia, complejidad de los clientes e incertidumbre que enfrentan (Alpha de 0.40 en la muestra nacional y 0.67 en la muestra metropolitana).

La variable tamaño está medida a través de la cantidad de empleados de la empresa y convertida a su forma logarítmica. Esto último tiene un 
doble objetivo, por un lado normalizar la distribución de la variable, que se caracteriza por una marcada skewness y, por otro, aprehender mejor la relación curvilínea entre tamaño y digitalización (incremento inicial más marcado que después se va atenuando).

Una explicación alternativa podría atribuir la falta de empleo de las TIC a la preocupación de la empresa por reducir costos, que frenaría tales inversiones. Atendiendo a esto hemos incluido una variable dummy que recoge la existencia en la empresa de una orientación estratégica de búsqueda de reducción de costos.

Otro factor que puede influir es el grado de entrenamiento del personal. Un personal más entrenado puede hacer más fácil y conveniente la introducción de estas tecnologías para la comunicación, dado que esa situación permite anticipar que serán mejor utilizadas. Al respecto, sin embargo, sólo pudimos incluir dos medidas indirectas con las que contábamos: el porcentaje de trabajadores entrenados durante el año previo en la base nacional, y la intensidad del entrenamiento recibido el año previo que reportan los trabajadores mismos, en la base metropolitana, mediante un índice con siete indicadores (Alpha $=0.81)$.

\subsection{Variables de control}

Controlamos la influencia del rubro de la empresa incluyendo la variable dummy pertenencia al sector servicios. Las características de los servicios, con la mayor centralidad que en ellos adquieren las relaciones personales hacen pensar que en estas empresas hay un ambiente más proclive al desarrollo de las comunicaciones interactivas y a un mayor empleo de las herramientas digitales para la comunicación. Además, dado que una de las muestras contiene sólo empresas de la Región Metropolitana, hemos chequeado en la muestra nacional el efecto de la pertenencia a esta región versus las restantes, lo cual se expresa en la variable dummy Región Metropolitana.

\subsection{Resultados}

En la Tabla $\mathrm{N}^{\circ} 6$ se registran las medias y desviaciones estándar de las variables consideradas, así como las correlaciones entre todas las variables $^{18}$. En la Tabla $\mathrm{N}^{\circ} 7$ y $\mathrm{N}^{\circ} 8$ se reportan los resultados obtenidos del

${ }^{18}$ Por razones de espacio sólo se han incluido los cálculos con respecto a la base nacional. En general los resultados de la muestra metropolitana son similares, salvo en algunos aspectos, que después quedan registrados en el análisis de regresión, donde los comentamos. 


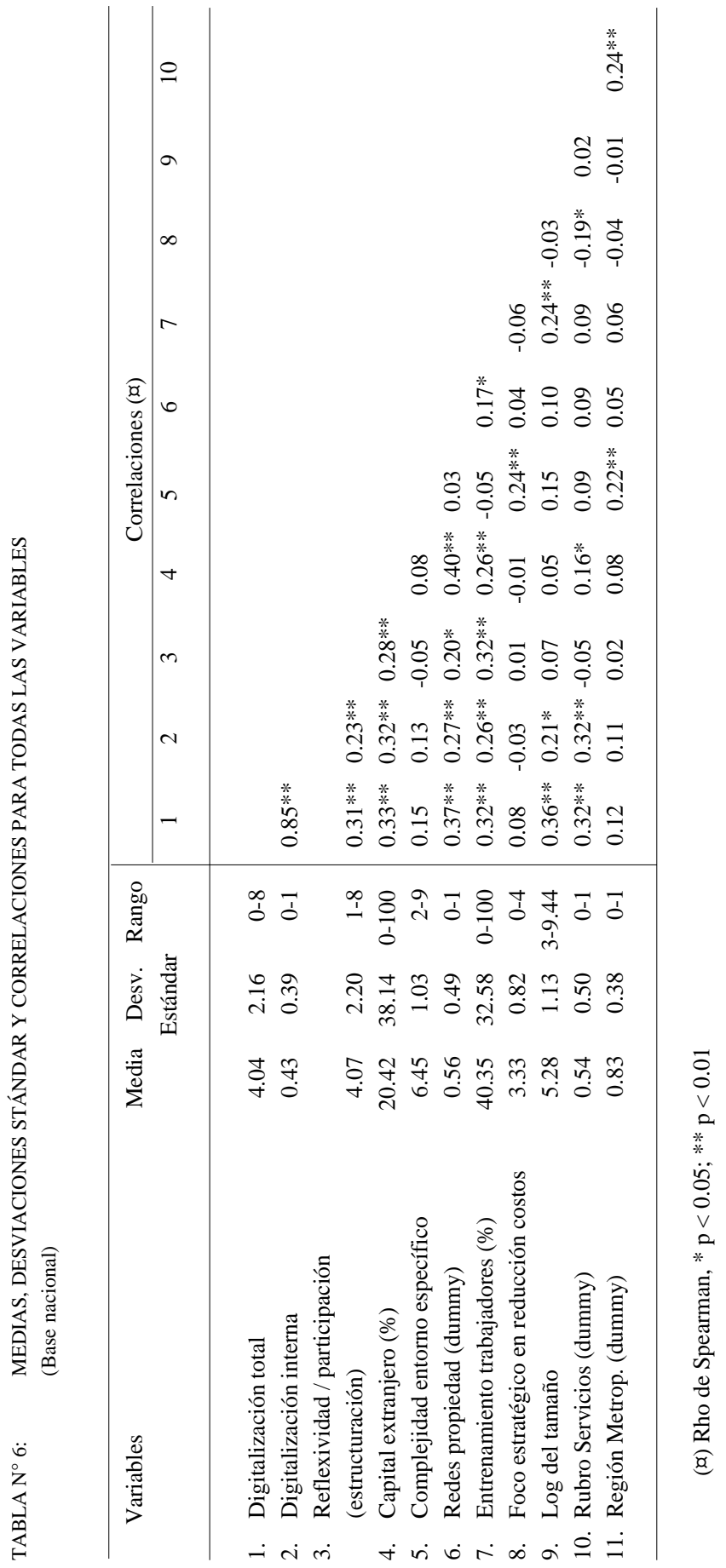


TABLA N ${ }^{\circ}$ 7: $\quad$ RESULTADOS DE ANÁLISIS DE REGRESIÓN MÚLTIPLE: DIGITALIZACIÓN DE LAS COMUNICACIONES INTERNAS DE LA EMPRESA Y SUS CONDICIONANTES

\begin{tabular}{|c|c|c|c|c|c|c|}
\hline \multirow[t]{2}{*}{ Variables independientes } & \multicolumn{3}{|c|}{ Muestra Nacional } & \multicolumn{3}{|c|}{ Muestra Metropolitana } \\
\hline & Modelo 1 & Modelo 2 & Modelo 3 & Modelo 1 & Modelo 2 & Modelo 3 \\
\hline $\begin{array}{l}\text { Reflexividad / } \\
\text { participación }\end{array}$ & $0.168 * *$ & $0.169 * *$ & $0.149 *$ & $0.329 * *$ & $0.273 *$ & $0.360 *$ \\
\hline Capital extranjero & $0.257 * *$ & $0.201 * *$ & $0.188 * *$ & 0.237 & 0.208 & 0.186 \\
\hline $\begin{array}{l}\text { Complejidad entorno } \\
\text { específico }\end{array}$ & 0.091 & 0.057 & 0.053 & $0.544 * * * *$ & $0.520 * * *$ & $0.523 * * *$ \\
\hline Entrenamiento trabajadores & & & 0.084 & & & 0.092 \\
\hline $\begin{array}{l}\text { Foco estratég. en reducción } \\
\text { costos }\end{array}$ & & & 0.011 & & & 0.127 \\
\hline Log del tamaño & & $0.197 * *$ & $0.181 * *$ & & 0.064 & 0.105 \\
\hline Rubro Servicios (dummy) & & $0.256 * * *$ & $0.253 * * *$ & & 0.201 & 0.220 \\
\hline Región Metrop. (dummy) & & & 0.012 & - & - & - \\
\hline $\mathrm{R}^{2}$ (ajustado) & 10.8 & 21.0 & 19.9 & 36.5 & 36.7 & 33.8 \\
\hline Número de casos & 144 & 144 & 144 & 30 & 30 & 30 \\
\hline
\end{tabular}

En la tabla se registran los coeficientes de regresión estandarizados.

$* \mathrm{p}<0.10$; ** $\mathrm{p}<0.05$; *** $\mathrm{p}<0.01$; **** $\mathrm{p}<0.001$. En todos los modelos $\mathrm{F}$ es significativo, $\mathrm{p}<0.001$.

TABLA N ${ }^{\circ}$ 8: $\quad$ RESULTADOS DE ANÁLISIS DE REGRESIÓN MÚLTIPLE: DIGITALIZACIÓN TOTAL DE LAS COMUNICACIONES DE LA EMPRESA (INTERNAS Y EXTERNAS) Y SUS CONDICIONANTES

\begin{tabular}{|c|c|c|c|c|c|c|c|}
\hline \multirow[t]{2}{*}{ Variables independientes } & \multicolumn{3}{|c|}{ Muestra Nacional } & \multicolumn{4}{|c|}{ Muestra Metropolitana } \\
\hline & Modelo 1 & Modelo 2 & Modelo 3 & Modelo 1 & Modelo 2 & Modelo 3 & Modelo 4 \\
\hline Capital extranjero (\%) & $0.211 * *$ & $0.132 *$ & $0.128 *$ & $0.493 * * *$ & 0.193 & 0.259 & 0.232 \\
\hline Redes de propiedad & $0.274 * * *$ & $0.169 * *$ & $0.167 * *$ & & 0.200 & 0.184 & 0.177 \\
\hline $\begin{array}{l}\text { Complejidad entorno } \\
\text { específico }\end{array}$ & 0.102 & 0.075 & 0.036 & $0.323 *$ & $0.359^{*}$ & $0.439 * *$ & $0.410 *$ \\
\hline $\begin{array}{l}\text { Reflexividad / participación } \\
\text { Entrenamiento }\end{array}$ & & $0.222 * * * *$ & $0.199 * * *$ & & & -0.065 & -0.049 \\
\hline $\begin{array}{r}\text { trabajadores }(\%) \\
\text { Foco estratégico en }\end{array}$ & & & 0.078 & & & 0.169 & 0.121 \\
\hline reducción costos & & & 0.102 & & & 0.258 & 0.255 \\
\hline Log del tamaño & & $0.328 * * * *$ & $0.317 * * * *$ & & & & 0.095 \\
\hline Rubro Servicios (dummy) & & $0.245 * * * *$ & $0.249 * * * *$ & & & & 0.017 \\
\hline Región Metrop. (dummy) & & & 0.060 & & & & \\
\hline $\mathrm{R}^{2}$ ajustado & 16.7 & 37.2 & 37.6 & 23.6 & 19.8 & 21.5 & 14.9 \\
\hline Número de casos & 150 & 144 & 144 & 31 & 31 & 30 & 30 \\
\hline
\end{tabular}

En la tabla se registran los coeficientes de regresión estandarizados.

$* \mathrm{p}<0.10$; ** $\mathrm{p}<0.05$; *** $\mathrm{p}<0.01$; **** $\mathrm{p}<0.001$. En todos los modelos $\mathrm{F}$ es significativo, $\mathrm{p}<0.001$. 
análisis de regresión múltiple realizado separadamente en las dos muestras. Estas dos últimas tablas contienen los coeficientes de regresión estandarizados (beta), que permiten comparar el peso relativo de cada variable, y su grado de significación estadística. Se incluyen diversos modelos que permiten apreciar el efecto de la introducción de las variables consideradas en las hipótesis así como el de las variables alternativas y de control.

\subsection{Análisis y discusión de resultados}

La primera hipótesis es sistemáticamente apoyada por los datos. Tal como conjeturábamos, la existencia de prácticas participativas, dando forma a una cultura de participación y reflexividad, es un factor que promueve o facilita un mayor y más complejo desarrollo de la digitalización de las comunicaciones internas en la empresa. La influencia de esta variable persiste aún después de la introducción de las variables de control, y es consistente en las dos muestras, con las dos formas diferentes de medición de la variable.

Adicionalmente, encontramos algo no planteado en la hipótesis. Esta variable, entendida como la institucionalización de la participación y reflexividad, y medida según la percepción gerencial, influye también en la digitalización total de la empresa, en la cual se incluyen prácticas de gestión y comunicaciones externas. Cuando se considera, en cambio, la cultura participativo-reflexiva expresada en las prácticas vividas por los trabajadores, en su propia percepción, no se da esta influencia sobre la digitalización total, sólo la antes mencionada sobre las comunicaciones internas.

Una explicación plausible, aunque ex post facto, de esto es la siguiente. Lo que ocurra con la aplicación de las TIC a las relaciones con clientes o a procesos de gestión no está necesariamente relacionado con la existencia de una cultura participativa. Por tanto la falta de relación con tal tipo de cultura, medida en la percepción de los trabajadores, aparece como un hecho esperable. Por su parte, la existencia de estructuración e institucionalización de procedimientos participativo-reflexivos, que reportan los gerentes, puede no estar cubriendo una cantidad importante del personal con lo cual se diferenciaría de lo recogido por los indicadores de la primera medida. Esta segunda medida sería más global y estructural, con menor sensibilidad a la cobertura de las prácticas participativas, mientras la medición basada en la percepción de los trabajadores detectaría principalmente esta cobertura e intensidad vivida de las prácticas. Vale decir, la existencia de tendencias a institucionalizar la participación y la reflexividad (ajeno a 
cuál sea su cobertura) es lo que también influiría sobre la digitalización generalizada de las comunicaciones en la empresa, internas y externas. Mientras que una cultura reflexiva-participativa vivenciada por cantidades importantes de trabajadores influiría fundamentalmente sobre la digitalización de las comunicaciones internas.

La segunda hipótesis — sobre la influencia de la conexión con empresas extranjeras - también se ve, en general, reforzada por los datos. En la muestra metropolitana, en todo caso, el respectivo coeficiente de regresión pierde significatividad estadística al introducir más variables; con una muestra de mayor tamaño los coeficientes se harían significativos $(\mathrm{p}<0.1)$, que es precisamente lo que ocurre en la muestra nacional.

Este es un segundo factor que podríamos llamar cultural, perteneciente a la cultura corporativa: se refiere a las orientaciones de gestión que se pueden prever son transmitidas a través de los vínculos de propiedad con empresas de países capitalistas avanzados.

En contraste a estos dos primeros factores, de índole cultural, la tercera variable independiente considerada, incluida en la tercera hipótesis, alude, por su parte, a un aspecto que podríamos llamar "técnico": la complejidad ambiental que enfrenta la empresa, en relación con otras empresas, con el mercado y clientes. En este caso, los resultados no son coincidentes entre ambas muestras, pese a que la medición de la variable es similar. La hipótesis es apoyada por los datos de la muestra metropolitana (son significativas las relaciones con la digitalización tanto interna como total) y contradicha por los datos de la muestra nacional. En el caso de la muestra nacional, no obstante, esta variable presenta una significativa aunque tenue correlación con la digitalización total $(\mathrm{r}=0.136, \mathrm{p}=0.052)$; pero cuando se introducen a la ecuación las variables tamaño y rubro esta relación prácticamente se disipa. Podría así pensarse que, en esta muestra, parte de los contenidos de complejidad e incertidumbre quedan mejor aprehendidos a través de estas dos variables: tamaño y rubro.

Pero si aducimos eso último, persiste la interrogante de por qué la relación se mantiene en la muestra metropolitana. Una explicación posible para estas diferencias es metodológica. En términos de medición hay un trade off entre ambas muestras. En la nacional, el tamaño muestral es mayor y se gana representatividad; pero son más limitadas las posibilidades para reforzar la confiabilidad ${ }^{19}$. En la metropolitana, en cambio, por ser un estudio intensivo, basado en entrevistas en profundidad, se gana en confiabilidad de las mediciones; pero la representatividad es menor. Podría así

${ }^{19}$ De hecho, en la muestra nacional, el índice para la variable "complejidad" es el que presenta un Alpha más bajo, indicando limitaciones en su confiabilidad. 
haber ocurrido que la interpretación dada, por los encuestados, a las preguntas sobre medio ambiente, en la muestra nacional, haya sido más imprecisa e introdujera un componente de error. De cualquier modo, aún sin invalidarse esta tercera hipótesis, el apoyo que recibe es sólo parcial.

La cuarta hipótesis, referida a la influencia de las redes de propiedad sobre la digitalización total, se ve apoyada por los datos empíricos. Se mantiene un valor alto y significativo del coeficiente de regresión, en los diferentes modelos. Los valores de los coeficientes de regresión de la muestra metropolitana son similares a los de la nacional ${ }^{20}$, aunque no alcanzan a ser significativos estadísticamente, debido al tamaño reducido de la muestra. Así, la pertenencia a redes de propiedad influye positivamente sobre la utilización generalizada de TIC en la empresa.

Finalmente, la quinta hipótesis, que es la más obvia, sobre la influencia del tamaño, se ratifica tal como era esperado.

Las explicaciones alternativas que consideramos, sobre la influencia de una orientación a la reducción de costos y del grado de entrenamiento del personal, no fueron sustentadas empíricamente.

A su vez, tampoco la variable región influye. Las diferencias, en el empleo de las TIC, que existan entre las empresas de la Región Metropolitana y de las otras regiones son explicadas por las otras variables incluidas. Esto, por lo demás, avala la utilidad explicativa de la muestra metropolitana de nuestra investigación.

Por tanto, los resultados encontrados muestran que la diversidad en usos de las TIC se explica en buena medida por características socioculturales de las empresas. Lo más destacable es el efecto de la participación y reflexividad: dado que en la mayoría de las empresas prevalece la carencia de participación y reflexividad, este factor estaría frenando un uso más intensivo y complejo de las TIC en las comunicaciones. La ausencia o debilidad en cuanto al diseño de instancias para la participación técnica, la falta de asignación de tiempo y las carencias en la estructuración de actividades que permitan revisar lo que se hace y recoger sistemáticamente las ideas y proyectos de los integrantes de la empresa, influye negativamente sobre el uso de las TIC para fines de comunicación e interacción. Esta situación obstaculizante va, claramente, más allá de las meras consideraciones técnicas. Gupta y Govindarajan (2000) hablan, en esa perspectiva, de la necesidad de montar una "ecología social" que permita sustentar la gestión del conocimiento. Se requiere, en particular, una estructuración del tiempo que contemple los espacios para la revisión y articulación de las experiencias de los trabajadores (Soo et al., 2002:141).

${ }^{20}$ Para el modelo con más variables, los coeficientes no estandarizados de las muestras metropolitana y nacional son 0.576 y 0.737 , respectivamente. 
Lo anterior ratifica que esta tecnología, por sí sola, no provoca la transformación de la empresa; no establece en ella redes de conocimiento, ni le injerta una inteligencia distribuida, ni desarrolla el aprendizaje organizacional. En tal sentido, hay mucha expectativa empresarial puesta en estas tecnologías que resulta ilusoria, en la medida que no se atienda, como se requiere, al sustrato sociocultural en que las TIC se insertan.

Comparativamente, en cambio, los factores técnicos y económicos no muestran la relevancia que suele atribuírseles, salvo en el caso del tamaño de la empresa, el cual en gran parte expresa la disponibilidad de recursos que ella tiene.

Como en toda investigación empírica, ésta tiene limitaciones, algunas de las cuales es conveniente anotar.

Hemos concentrado la atención en un aspecto de la cultura corporativa - la dimensión participativo-reflexiva - que consideramos crucial para las actuales transformaciones de la empresa (cf. Ramos, 2004). Pero podría aducirse que sería necesario considerar otros aspectos de la cultura interna de las empresas. En particular, podría considerarse que la confianza puede facilitar o estimular el empleo de las TIC al servicio de las comunicaciones internas. En contraste, un ambiente de desconfianza haría anticipar problemas y tendería a disuadir a los sectores gerenciales de incorporarlas.

Sin entrar al debate sobre si la confianza es un componente de la cultura o del clima organizacional, creemos que su efecto es más complejo que eso. De hecho, los resultados de nuestro estudio en profundidad nos hacen pensar que existe una gama de situaciones que no se ajusta fácilmente al modelaje matemático. Hay casos de baja confianza, donde las empresas (por ejemplo en rubros avanzados) crean contextos organizacionales altamente tecnologizados, en los cuales la comunicación digital aparece como reemplazo o sucedáneo de las relaciones interpersonales, que son débiles y reducidas. Al mismo tiempo, las comunicaciones digitales en tales condiciones están más proclives a ser usadas al servicio del control que de la participación y colaboración (MG10, SG31). Hay otros casos de alta confianza donde ésta se traduce, efectivamente, en un amplio e intenso empleo de las TIC al servicio de las comunicaciones internas, y del establecimiento de relaciones de colaboración y reflexividad (SG21). Un tercer tipo de casos, finalmente, presentan lo que podríamos denominar una confianza paternalista: los sectores gerenciales mantienen relaciones personalistas, fomentando lealtades individuales hacia la gerencia. En tal contexto la gerencia promueve la comunicación personal de índole vertical. La comunicación digital, con sus potencialidades de interactividad y de amplia 
comunicación horizontal no es vista como atractiva por los gerentes y más bien estiman que puede ser eventualmente disruptora de esas pautas tradicionales (MG18, SM23) ${ }^{21}$.

La falta de efecto que muestra la variable entrenamiento podría deberse a problemas en su medición. Tal como indicamos, sólo contábamos con una medida indirecta. El uso de mejores indicadores podría revelar que sí tiene efecto.

Otra limitante que debe tenerse en cuenta es que la mirada de este estudio ha estado dirigida hacia los factores referidos a las empresas, internamente o en sus interconexiones, que puedan incidir en el uso de las TIC. No hemos considerado aquí, en cambio, los factores institucionales externos. Al respecto, al menos debe destacarse el rol que en Chile está teniendo el Estado, con una activa acción en el campo del e-government y de la difusión de estas tecnologías ${ }^{22}$.

\section{Conclusiones sobre la adopción organizacional de las TIC}

Las TIC ya se han hecho parte del funcionamiento organizacional de las empresas chilenas, siendo aplicadas de manera importante a los procesos de trabajo y a la gestión. Igualmente, se ha desarrollado la conectividad externa. Todo ello sitúa a las empresas chilenas en posiciones avanzadas con respecto a América Latina. En el contexto mundial, por su parte, Chile aparece como un país que ha mantenido un rápido ritmo de adopción de esta tecnología, lo cual lo mantendría no demasiado lejos de los países capitalistas avanzados (Cámara de Comercio de Santiago, 2002-2003).

No obstante eso, el desarrollo de estas tecnologías ha sido mucho más débil en cuanto a la generación de espacios digitales de interacción, en la constitución de equipos de trabajo virtuales y, en general, en el empleo de las TIC para la gestión del conocimiento y la reflexividad organizacional. En esta materia, las empresas chilenas muestran un estado deficitario y las proyecciones de desarrollo no parecen alentadoras. Se han privilegiado los usos tradicionales de esta tecnología, para la generación y acumulación de datos, como apoyo a la toma de decisiones, y como forma de sistemati-

${ }^{21}$ Para un futuro estudio, incluyendo la variable confianza, tal variedad de tipos de influencia podría tentativamente modelarse por medio de una forma cuadrática.

22 Diversos estudios internacionales, tales como los de la Brown University y Harvard University, han colocado al Estado chileno en lugares destacados a nivel mundial en cuanto al desarrollo de actividades de gobierno por medio de las TIC (Cámara de Comercio de Santiago, 2003:89, 90). Tales actividades gubernamentales sirven de modelo a las empresas y contribuyen a la difusión de estas tecnologías. 
zar procesos de gestión, mientras que en relación al personal, su uso ha estado, de manera destacada, al servicio del control. El resultado, así, es una adopción parcial y desbalanceada de estas tecnologías.

En contra de lo que es más habitual escuchar, los resultados de esta investigación muestran que las principales explicaciones de esta situación, en el caso de las empresas medianas y grandes, no radican en factores económicos o técnicos. Algunos de los principales factores corresponden a la cultura organizacional de las empresas. La falta de culturas e institucionalidades participativas en las empresas estaría dificultando el desarrollo de la digitalización al servicio de la interactividad comunicativa interna. Por otra parte, el uso creciente de las TIC para el control del trabajo y de los trabajadores, según las informaciones cualitativas obtenidas, también parecería asociado a esos rasgos culturales. En ese contexto, este mayor control informático tendería, a su vez, a reforzar el verticalismo y la desconfianza.

Dos factores que, según los datos, promueven una digitalización más intensa y sofisticada de las comunicaciones son que la empresa sea parte de redes de propiedad $\mathrm{y}$, en particular, que tenga conexiones de propiedad con empresas extranjeras, de países de capitalismo avanzado. Ambos aspectos remiten a conexiones de redes, aunque involucran algunas diferencias. En el caso de la conexión con empresas extranjeras, la red opera como medio para canalizar las orientaciones culturales de tales empresas en cuanto a la valoración y práctica de la participación y reflexividad interna de la empresa. Influiría preferentemente, por tanto, sobre la digitalización interna - lo cual, según los datos, es el caso- La pertenencia a redes de propiedad, por su parte, plantea un imperativo técnico de mayor y mejor coordinación interorganizacional, para lo cual las TIC aparecen como una herramienta privilegiada. Influye, así, en la digitalización total básicamente a través de su estímulo de la digitalización de las relaciones externas.

En conclusión, los usos principales que las empresas chilenas les dan actualmente a las TIC están referidos a la acumulación de datos, manejo de información y control del trabajo. Todavía es muy incipiente y poco sistemático, en contraste, el uso al servicio de la gestión del conocimiento, la reflexividad y la innovación. La existencia de factores socioculturales asociados a las dificultades para tales usos avanzados hace necesario plantear que no cabe esperar que el cambio en el uso de las TIC provenga meramente de mejores condiciones técnicas o económicas, o de apoyos en estos aspectos. Ineludiblemente, se requieren transformaciones más globales en las prácticas de las empresas, las cuales, a su vez, están asociadas a sus culturas e institucionalidades internas. 


\section{REFERENCIAS BIBLIOGRÁFICAS}

American Management Association: Workplace Testing: Monitoring and Surveillance. New York: AMA, 2000.

American Management Association: 2003 E-Mail Rules, Policies and Practices Survey. New York: AMA, 2003.

Amin, Ash: "Post-Fordism: Models, Fantasies and Phantoms of Transition". En Ash Amin (ed.), Post-Fordism. A Reader. Oxford, UK: Blackwell, 1994.

Appelbaum, Eileen y Rosemary Batt: The New American Workplace. Transforming Work Systems in the United States. New York: ILR Press (Cornell University), 1994.

Beck, Ulrich, Anthony Giddens y Scott Lash: Modernización Reflexiva. Madrid: Alianza Editorial, 1997.

Blom, Raimo y Harri Melin: "Information Society and the Transformation of Organizations in Finland". Work and Occupations, 30(2): 176-193, 2003.

Boyer, Robert y Jean-Pierre Durand: After Fordism. London: MacMillan Press, 1997.

Cámara de Comercio de Santiago: La Economía Digital en Chile. 2002. Santiago, Chile: Editorial Cámara de Comercio de Santiago, 2002.

Cámara de Comercio de Santiago: La Economía Digital en Chile. 2003. Santiago, Chile: Editorial Cámara de Comercio de Santiago, 2003.

Castells, Manuel: The Rise of the Network Society. Malden, Mass.: Blackwell Publishers, 1996.

Castells, Manuel: La Galaxia Internet. Barcelona: Plaza \& Janés Editores, 2001.

Constant, David, Lee Sproull y Sara Kiesler: "The Kindness of Strangers: On the Usefulness of Electronic Weak Ties for Technical Advice”. En Sara Kiesler (ed.), Culture of the Internet. Mahwah, New Jersey: Lawrence Erlbaum Associates, Publishers, 1997.

Charles, Tony: "The New Division of Labour in Europe". En Littek, Wolfgang \& Tony Charles (eds.). The New Division of Labour. Emerging Forms of Work Organization in International Perspective. Berlin: Walter de Gruyter, 1995.

Davenport, Thomas y Laurence Prusak: Working Knowledge: How Organizations Manage What They Know. Boston: Harvard Business School Press, 2000.

Dohse, Knuth, Ulrich Jurgens y Thomas Malsch: "From 'Fordism' to 'Toyotism'? The Social Organization of the Labor Process in the Japanese Automobile Industry." Politics and Society, 14 (2): 115-146, 1985.

Gupta, Anil y Vijay Govindarajan: “Knowledge Management's Social Dimension: Lessons From Nucor Steel”. Sloan Management Review. Fall: 71-80, 2000.

Hinds, Pamela y Sara Kiesler: "Communication Across Boundaries. Work, Structure, and Use of Communication Technologies in a Large Organization”. En Gerardine DeSanctis y Janet Fulk (eds.), Shaping Organization For. Communication, Connection and Community. London: Sage Publications, 1999.

Hollingsworth, J. Rogers y Robert Boyer (eds.): Contemporary Capitalism. The Embeddedness of Institutions. Cambridge: Cambridge University Press, 1997.

Kenney, Martin y Richard Florida: Beyond Mass Production. The Japanese System and Its Transfer to the U.S. New York: Oxford University Press, 1993.

Lawler, Edward E., Susan Mohrman y Gerald Ledford: Strategies for High Performance Organizations. Employee Involvement, TQM, and Reengineering Programs in Fortune 1000 Corporations. San Francisco: Jossey-Bass Publishers, 1998. 
Martínez, María Luisa y Sebastián Pérez: “Tecnología Informativa en Procesos de Comunicación y Gestión: Caso BancoEstado". Tesis de Titulación en Sociología. Santiago: Universidad Católica de Chile.

McDermott, R.: "Why Information Technology Inspired But Cannot Deliver Knowledge Management". California Management Review. 41(4): 103-117, 1999.

OIT: Informe sobre el Empleo en el Mundo 2001. La Vida en el Trabajo en la Economía de la Información. Ginebra: Oficina Internacional del Trabajo, 2002.

Orlikowski, Wanda: "Evolving with Notes: Organizational Change around Groupware Technology". En Claudio Ciborra, Groupware \& Teamwork. Invisible Aid or Technical Hindrance. Chichester, England: John Wiley \& Sons, pp. 23-59, 1996.

Orlikowski, Wanda, Joanne Yates, Kazuo Okamura y Masayo Fujimoto: "Shaping Electronic Communication: The Metastructuring of Technology in the Context of Use". En Gerardine DeSanctis y Janet Fulk (eds.), Shaping Organization for Communication, Connection and Community. London: Sage Publications, 1999.

Orlikowski, Wanda y Stephen Barley: "Technology and Institutions: What Can Research on Information Technology and Research on Organizations Learn from Each Other?". MIS Quarterly, 25(2): 145-165, 2001.

Papows, Jeff: Enterprise.com. Market Leadership in the Information Age. Reading, Mass.: Perseus Books, 1998.

Piore, Michael y Charles Sabel: The Second Industrial Divide. New York: Basic Books Publishers, 1984.

Ramos, Claudio: "La Experiencia de los Trabajadores Frente al Cambio Organizacional, en Empresas Manufactureras y de Servicio". Persona y Sociedad. 17(4): 111-150, 2003.

Ramos, Claudio: "Innovación en la Gestión Organizacional de las Empresas Chilenas". Santiago, Chile: Universidad Alberto Hurtado, 2004. Inédito.

Soo, Christine, Timothy Devinney, David Midgley y Anne Deering: "Knowledge Management: Philosophy, Processes, and Pitfalls". California Management Review. 44(4): 129-150, 2002.

Subsecretaría de Economía: Acceso y Uso de Tecnologías de Información en las Empresas Chilenas. Santiago, Chile: Ministerio de Economía, 2002.

Womack, James, Daniel Jones y Daniel Roos: The Machine that Changed the World. New York: MacMillan, 1990. 